Esta obra forma parte del acervo de la Biblioteca Jurídica Virtual del Instituto de Investigaciones Jurídicas de la UNAM

\title{
CONTROL CONSTITUCIONAL DE LAS \\ LEYES ELECTORALES ${ }^{1}$
}

CONSTITUTIONAL CONTROL

OFELECTORAL LAW

Roberto DUQUE ROQUERO ${ }^{2}$

\section{Sumario:}

\section{Esbozo conceptual}

II. Control de constitucionalidad de leyes en México

III. Control de constitucionalidad de leyes electorales

IV. Reforma electoral 2007-2008

V. Inaplicación de normas electorales por el Tribunal Electoral del Poder Judicial de la Federación

VI. Alcances y límites del control

VII. Conclusiones

Resumen: El sistema jurídico mexicano cuenta con un modelo mixto de control de constitucionalidad de leyes. Por un lado, se efectúa un control concreto en el que la norma que se juzga inconstitucional es inaplicada sólo para el caso específico que se resuelve (efectos inter partes), pero continúa vigente. En otros casos se realiza un control abstracto, con la consecuente invalidez de una norma si resultara ser contraria a la Constitución, lo cual produce efectos generales (erga omnes).

Esto lo vemos reflejado en el actual control constitucional de normas electorales de nuestro país, cuyas limitantes son: 1) el amparo contra leyes previsto en los artículos 103 y 107 constitucionales es improcedente en contra de normas electorales; 2) los ciudadanos comunes no están legitimados activamente para ejercitar la acción de inconstitucionalidad

${ }^{1}$ El presente artículo se enmarca en la tesis de doctorado que el autor realiza, inscrita en el Departamento de Derecho Constitucional de la Facultad de Derecho en la Universidad Complutense de Madrid.

${ }^{2}$ Abogado especializado en democracia y derecho constitucional; profesor en la Facultad de Derecho de la Universidad Nacional Autónoma de México y coordinador de Asesores del Abogado General de la UNAM. 
Esta obra forma parte del acervo de la Biblioteca Jurídica Virtual del Instituto de Investigaciones Jurídicas de la UNAM www.juridicas.unam.mx

que conforme al artículo 105 constitucional, es la única vía para plantear la no conformidad de leyes electorales a la Constitución, y 3) el tipo de control que realiza el Tribunal Electoral del Poder Judicial de la Federación, en adelante TEPJF, es de carácter concreto, por lo que los efectos de sus sentencias se limitan a las partes que contienden en un juicio específico.

Esto genera un problema de seguridad jurídica en el ciudadano ante una norma electoral que lesione sus derechos fundamentales. Es necesario que se establezca en el artículo 99 constitucional la posibilidad de que el TEPJF efectúe un control abstracto, de modo que sus sentencias produzcan efectos generales.

Palabras clave: justicia constitucional, control constitucional, elecciones, justicia electoral, acceso a la justicia.

ABSTRACT: The Mexican legal system has a mixed model of constitutional review. On one hand, there is a concrete control in which the norm deemed unconstitutional is no longer applied to the specific case (an inter partes effect); nevertheless, it remains in force. On the other hand, there is an abstract control that results in the invalidity of the norm whenever it is found contrary to the constitution, which has a general effect (erga omnes).

This can be observed in the current system of constitutional control of electoral norms in our country, essentially limited due to: 1) The writ of Amparo in Mexico, established in articles 103 and 107 of the constitution, is inadmissible in electoral matters; 2) Regular citizens lack standing to present actions of unconstitutionality which, according to article 105 , is the only means to claim the non-conformity of electoral laws to the Constitution; and 3) The kind of control performed by the Electoral Tribunal of the Federal Judicial Branch (TEPJF, Tribunal Electoral del Poder Judicial de la Federación, in Spanish) is concrete, which means that its rulings' effects are limited to the parties of a specific trial.

This creates a problem of legal certainty for citizens before electoral norms that violate their fundamental rights. It is necessary for article 99 of the constitution to grant the TEPJF the authority to exercise an abstract control, so that its rulings may have general effects.

Descriptors: constitutional justice, constitutional review, elections, electoral justice, access to justice.

\section{ESBOZO CONCEPTUAL}

Una de las cuestiones centrales del derecho constitucional es el control de constitucionalidad de las leyes. ¿Qué ocurre si una ley es contraria a la Constitución? ¿Puede el Poder Judicial corregir el error del Legislativo? De acuerdo con la conocida pirámide de jerarquía normativa, en el vértice superior se localiza la Constitución, norma fundamental y ordenadora de todo el sistema jurídico, y el resto del derecho debe estar 
Esta obra forma parte del acervo de la Biblioteca Jurídica Virtual del Instituto de Investigaciones Jurídicas de la UNAM

acorde con ella. De poco serviría esa codificación si alguna autoridad en específico pudiera modificar a su antojo el funcionamiento del Estado y las competencias asignadas.

La Constitución, de hecho, debe entenderse como una manifestación jurídica de la democracia, por eso es tan relevante la necesidad de que existan mecanismos que garanticen su hegemonía y supriman cualquier norma que esté en contradicción con ella. Como lo apunta Pedro de Vega, el Estado constitucional se edifica en dos pilares fundamentales: en el principio político democrático de soberanía popular y en el principio jurídico de supremacía constitucional. ${ }^{3}$ Por lógica elemental, al ser promulgadas las leyes por asambleas legislativas, es necesario encomendar la función del control a órganos distintos. Ese es el origen de la jurisdicción constitucional.

\section{Control difuso y control concentrado:}

¿quién realiza el control?

La doctrina distingue dos tipos de control de la constitucionalidad de las leyes por cuanto a la jurisdicción que lo efectúa. El control difuso, en primer lugar, es un sistema en el que se autoriza a cualquier tribunal para declarar inaplicable una ley (u otras disposiciones de menor jerarquía) que se estimen contrarias a la Constitución. Por el otro lado, el control concentrado encomienda ese tipo de función a un órgano jurisdiccional ad hoc.

El primero de estos modelos — control difuso - tuvo origen en la llamada doctrina de la judicial review of legislation (revisión judicial de la legislación). En Inglaterra se encuentra un antecedente remoto (caso Bonham, 1610) en el que el juez Edward Coke subrayaría la supremacía del Common Law sobre la autoridad parlamentaria. Con posterioridad, en Estados Unidos los escritos de Hamilton, Madison y Jay, que integrarían la obra El Federalista, incorporaron la discusión de la judicial review. Hamilton en particular justificaba la atribución de los tribunales en la función de interpretar leyes, dando preeminencia a la Constitución en el supuesto de que se produjera una discrepancia entre ésta y cualquier ley ordinaria que proviniera del cuerpo legislativo. ${ }^{4}$

La actuación del juez John Marshall definió en buena medida el sistema, en especial

\footnotetext{
${ }^{3}$ Vega, Pedro de, La reforma constitucional y la problemática del Poder Constituyente, Madrid, Tecnos, 1988, p. 15.

${ }^{4}$ Sobre este particular, se recomienda el estudio pormenorizado de Fernández Segado, Francisco, El sistema constitucional español, España, Dykinson, 1992, pp. 138 y 139.
} 
Esta obra forma parte del acervo de la Biblioteca Jurídica Virtual del Instituto de Investigaciones Jurídicas de la UNAM

con la célebre sentencia al caso Marbury vs. Madison dictada en 1803, en la que interpretó la supremacía constitucional prevista en el artículo VI, sección segunda, de la Constitución Federal de Estados Unidos. Marshall sostuvo que una "ley" contraria a la Constitución no puede considerarse siquiera como tal, y que ningún juez queda obligado por ella. A partir de entonces se consolidó el llamado "modelo americano".

A más de un siglo de distancia se configuraría, en contraste, el modelo del control concentrado de constitucionalidad por obra del pensamiento de Hans Kelsen, quien rehízo el principio de supremacía de la Constitución. La idea central del jurista austriaco residió en la necesidad de establecer un órgano ajeno al Poder Judicial, ya que la autoridad encargada de determinar si una ley es válida o no por definición se encuentra por encima de las leyes. En tanto que los poderes públicos (en particular los tres poderes clásicos: Legislativo, Ejecutivo y Judicial) deben cumplir la ley y, por tanto, subordinarse a ella, ninguno podría ser el encargado de la función de control de su constitucionalidad sin que se produjera un desequilibrio (se alteraría el sistema de pesos y contrapesos que supone el principio de división de poderes).

Por lo anterior, se planteó la creación de una institución que tuviera ese propósito exclusivo, denominada Tribunal Constitucional, la cual existió por primera vez en la Constitución austriaca de 1920. Se trata de un órgano jurisdiccional especializado e independiente de los demás poderes, incluido el judicial. En efecto, la concepción de un Tribunal Constitucional como "guardián de la Constitución" implica un órgano derivado directamente de la carta fundamental, y que se encuentra bien diferenciado de las jurisdicciones ordinarias.

Es así que los dos modelos clásicos (el americano y el austriaco) tienen rasgos claramente distintos y son el punto de referencia en el control constitucional de la legislación. ${ }^{5}$ Por supuesto que, entre un sistema y otro, se han desarrollado formas mixtas de justicia constitucional, en las que coexisten elementos distintivos de cada uno. Por ejemplo, a decir de Giancarlo Rolla, en América Latina se presenta un "verdadero laboratorio de formas peculiares de justicia constitucional:" en algunos países convive el

\footnotetext{
${ }^{5}$ Acerca de los rasgos fundamentales de ambos modelos (americano y europeo) véase también el estudio realizado por Fix-Zamudio, Héctor y Ferrer Mac-Gregor, Eduardo, "Las sentencias de los tribunales constitucionales en el ordenamiento mexicano", Anuario Iberoamericano de Justicia Constitucional, Madrid, Centro de Estudios Políticos y Constitucionales, 2008, pp. 202 y ss.
} 
Esta obra forma parte del acervo de la Biblioteca Jurídica Virtual del Instituto de Investigaciones Jurídicas de la UNAM www.juridicas.unam.mx

control concentrado ante un tribunal constitucional con el control difuso:

Los sistemas 'centralizados' parecieran abrirse a formas de convivencia con la judicial review, como lo evidencia la realidad del reciente constitucionalismo ibero-americano, que algunos autores han definido 'difuso concentrada' (García Belaúnde), por el otro lado, los sistemas 'difusos' registran una tendencia de las cortes supremas a monopolizar el ejercicio de la jurisdicción constitucional, acentuando los elementos de centralización sustancial. ${ }^{6}$

Este último ha sido precisamente el caso de México. La Suprema Corte de Justicia de la Nación (SCJN) asumió desde 1994 funciones de tribunal constitucional, aunque no del todo, ya que los jueces y tribunales ordinarios deben aplicar sólo normas que no estén en contradicción con la carta fundamental, de manera que tienen intervención en el control constitucional, como se precisará más adelante.

\section{Control abstracto y control concreto}

Se denomina control abstracto de constitucionalidad de una norma a la declaración de invalidez de la misma en caso de ser contraria a la ley suprema, es decir, la disposición queda expulsada del ordenamiento $\mathrm{y}$, por consiguiente, tiene efectos generales (erga omnes). En sentido contrario, el control concreto se presenta si la norma que se considera inconstitucional es inaplicada al caso específico que se resuelve pero mantiene su vigencia, de modo que el fallo tendrá sólo efectos particulares (inter partes).

Así, el control concreto es característico del modelo estadounidense (control difuso de la constitucionalidad), y el control abstracto es propio del modelo austriaco y lo realiza un tribunal constitucional (control concentrado). ${ }^{7}$ José Ramón Cossío lo explica de la siguiente manera:

Por una parte, la modalidad que podemos llamar 'control concentrado' es aquella en la que los órganos del Estado analizan las posibles contradicciones de una norma general frente a la Constitución a efecto de declarar, en la parte resolutiva del fallo, la nulidad de la primera. Por otra parte, aquella que suele denominarse 'control difuso', donde el órgano que lleva a

${ }^{6}$ Rolla, Giancarlo, "La tutela directa de los derechos fundamentales por los tribunales constitucionales", Anuario Iberoamericano de Justicia Constitucional, Madrid, Centro de Estudios Políticos y Constitucionales, 2008, p. 310.

${ }^{7}$ También pueden clasificarse los efectos de las sentencias en relación con el tiempo: a) ex tunc, si generan efectos hacia el pasado (propio del sistema americano), y b) ex nunc, si generan efectos a partir del momento del fallo (propio del modelo austriaco). 
Esta obra forma parte del acervo de la Biblioteca Jurídica Virtual del Instituto de Investigaciones Jurídicas de la UNAM www.juridicas.unam.mx

cabo el control de constitucionalidad aprecia la posible contradicción entre ley y Constitución en la parte considerativa del fallo, con lo cual llega a desaplicarla para el caso concreto sin hacer una declaración general de nulidad de la misma. ${ }^{8}$

A primera vista, un inconveniente en el modelo de control concreto radica en que la ley que sea contraria a la Constitución tendrá efectos sólo para las partes en disputa, de modo que la misma ley sería "inconstitucional" para quien la impugne y obtenga un fallo favorable, y "constitucional" para los demás. Pero es necesario precisar que en el modelo americano existen otras características que contribuyen a compensar este problema, como es el principio stare decisis (vinculación del precedente). Esto implica, en la práctica, que los criterios perduren en el tiempo y se apliquen en lo sucesivo. De esta manera se logra en alguna medida que los efectos de las sentencias se generalicen.

Si bien es cierto que el control abstracto brinda una mayor seguridad jurídica a los ciudadanos por las razones antes señaladas (efectos erga omnes), muchos estudiosos han alertado el riesgo de llegar a lo que se ha denominado "el gobierno de los jueces" o la posibilidad de que el juez constitucional se convierta - sin más- en un "legislador negativo". En efecto, la tarea que implica la completa invalidez de la disposición legal, exige una mayor responsabilidad del juez, ya que una equivocación ¡también tendría efectos erga omnes! La exigencia de una mayoría calificada en los tribunales que controlan la constitucionalidad de las leyes ayuda a que esto no suceda.

\section{CONTROL DE CONSTITUCIONALIDAD DE LEYES EN MÉXICO}

Siguiendo a Héctor Fix-Zamudio, en México existen distintas garantías constitucionales que la Constitución prevé para su defensa que son medios jurídicos, predominantemente de carácter procesal dirigidos a la reintegración del orden constitucional cuando éste ha sido vulnerado por los propios órganos de poder. En su conjunto, hay diversas garantías que constituyen lo que dicho autor denomina derecho procesal constitucional mexicano y se ilustran en el cuadro siguiente:

${ }^{8}$ Cossío Díaz, José Ramón, "El indebido monopolio constitucional-electoral de la Suprema Corte de Justicia", Revista Este País, México, núm. 139, octubre de 2002, p 36.

9 Fix-Zamudio, Héctor, Justicia constitucional, Ombudsman y derechos humanos, México, Comisión Nacional de Derechos Humanos, 1997, pp. 325 y 326; citado en Terrazas Salgado, Rodolfo, Introducción al estudio de la justicia constitucional electoral en México, México, Ángel Editor, 2006, pp. 55-57. 
Esta obra forma parte del acervo de la Biblioteca Jurídica Virtual del Instituto de Investigaciones Jurídicas de la UNAM www.juridicas.unam.mx tps://biblio.juridicas.unam.mx/bjv https://revistas.juridicas.unam.mx/

DOI: http://dx.doi.org/10.22201/iij.24487910e_2015.7.10086

Defensa de la Constitución: garantías constitucionales (Fix-Zamudio)

\begin{tabular}{|l|l|l|}
\hline Procedimiento & $\begin{array}{l}\text { Disposición } \\
\text { constitucional }\end{array}$ & Órganos competentes \\
\hline El juicio político & (artículo 110) & $\begin{array}{l}\text { Congreso de la Unión } \\
\text { (ambas cámaras) }\end{array}$ \\
\hline $\begin{array}{l}\text { Las controversias } \\
\text { constitucionales }\end{array}$ & $\begin{array}{l}\text { artículo 105, fracción } \\
\text { I }\end{array}$ & SCJN \\
\hline $\begin{array}{l}\text { La acción abstracta de } \\
\text { inconstitucionalidad }\end{array}$ & $\begin{array}{l}\text { artículo 105, fracción } \\
\text { II }\end{array}$ & SCJN \\
\hline $\begin{array}{l}\text { El procedimiento investigatorio } \\
\text { de la Suprema Corte de Justicia } \\
\text { de la Nación }\end{array}$ & $\begin{array}{l}\text { artículo 97, párrafo } \\
\text { segundo }\end{array}$ & SCJN \\
\hline $\begin{array}{l}\text { El juicio de amparo de revisión } \\
\text { El juicio para la protección de } \\
\text { los derechos político- } \\
\text { electorales de los ciudadanos }\end{array}$ & $\begin{array}{l}\text { artículo 99, fracción } \\
\text { IV }\end{array}$ & TEPJF \\
\hline $\begin{array}{l}\text { El juicióculo 99, fracción V } \\
\text { constitucional electoral }\end{array}$ & TEPJF \\
\hline $\begin{array}{l}\text { Los organismos autónomos } \\
\text { protectores de los derechos } \\
\text { humanos }\end{array}$ & $\begin{array}{l}\text { artículo } \\
\text { apartado B }\end{array}$ & Poder Judicial \\
\hline
\end{tabular}

Además de estas garantías constitucionales, Fix-Zamudio expresa que existe otro sector en la defensa constitucional integrado por todos aquellos instrumentos políticos, económicos, sociales y de técnica jurídica que han sido canalizados a través de normas de carácter fundamental e incorporados a los documentos constitucionales, con el propósito de limitar el poder y lograr que sus titulares se sometan a los lineamientos

\footnotetext{
${ }^{10}$ Con la reforma electoral de 1997 se derogó el párrafo tercero del artículo 97 constitucional, el cual también integraba este sector. Dicho dispositivo facultaba a la SCJN para la averiguación de hechos que constituyeran violaciones del voto público cuando a su juicio pudiera ponerse en duda la legalidad de todo el proceso de elección de alguno de los poderes de la Unión.
} 
Esta obra forma parte del acervo de la Biblioteca Jurídica Virtual del Instituto de Investigaciones Jurídicas de la UNAM

establecidos en la propia Constitución. ${ }^{11}$

Se advierte que en el desahogo de estos mecanismos intervienen diversas autoridades del Estado, en todos los casos para conservar la normativa constitucional y prevenir su violación. Para los efectos de este trabajo, destacan las competencias de la Suprema Corte de Justicia de la Nación (SCJN) en lo referente a la acción de inconstitucionalidad y las del Tribunal Electoral del Poder Judicial de la Federación (TEPJF) en los juicios para la protección de los derechos político-electorales del ciudadano y de revisión constitucional electoral. Veamos estos rubros a detalle.

\section{La acción de inconstitucionalidad}

De acuerdo con el artículo 105 constitucional, fracción II, la Suprema Corte conocerá de las acciones de inconstitucionalidad que tengan por objeto plantear la posible contradicción entre una norma de carácter general y la Constitución, las cuales podrán ejercitarse dentro de los 30 días naturales siguientes a la fecha de publicación de la norma.

Como ya lo hemos adelantado, en México existe un sistema mixto de control de constitucionalidad que se encuentra en una zona intermedia entre los modelos clásicos estadounidense y austriaco. A partir de las reformas a la jurisdicción constitucional mexicana publicadas en el Diario Oficial de la Federación el 31 de diciembre de 1994, la SCJN tiene facultades propias de un tribunal constitucional, no obstante, conservó también funciones que no corresponden a ese tipo de órgano en sentido propio. ${ }^{12}$

El catálogo de sujetos legitimados para promover una acción de inconstitucionalidad es limitativo y se define en la propia fracción II del artículo 105 de la carta fundamental: sólo pueden acudir por esta vía a la SCJN las minorías parlamentarias que precisa el artículo: el Ejecutivo federal; los partidos políticos (nacionales o locales) en contra de leyes electorales; las comisiones de derechos humanos (nacional o de las entidades federativas); el Instituto Federal de Acceso a la Información y Protección de Datos, y el fiscal general de la República, si la ley en cuestión les incumbe.

En lo referente a las leyes electorales, además de que sólo los partidos políticos

\footnotetext{
${ }^{11}$ Fix-Zamudio, H. Ibid.

12 Para analizar la problemática que genera esta dualidad de la Suprema Corte mexicana, véase Carbonell, Miguel, Constitucionalismo y democracia, ensayos críticos, México, Porrúa, 2004, pp. 134 y ss.
} 
Esta obra forma parte del acervo de la Biblioteca Jurídica Virtual del Instituto de Investigaciones Jurídicas de la UNAM

pueden plantear una acción de inconstitucionalidad (no así los ciudadanos, titulares de derechos político-electorales), el artículo 105 señala que para plantear la no conformidad de las leyes electorales a la Constitución sólo hay una vía y es esa. ${ }^{13}$ Al respecto, la SCJN ha precisado qué debe entenderse por normas generales electorales: no sólo son las que establecen el régimen normativo de los procesos electorales sino también las que regulan aspectos vinculados directa o indirectamente con dichos procesos o que deban influir en ellos de una manera o de otra (aunque estén contenidas en ordenamientos distintos a una ley o código electoral). Por ejemplo: la distritación o redistritación; la creación de órganos administrativos para fines electorales; la organización de las elecciones; el financiamiento público; la comunicación social de los partidos; los límites de las erogaciones y montos máximos de aportaciones; los delitos y faltas administrativas, y sus sanciones, entre otros puntos. ${ }^{14}$

Ahora bien, en cuanto a los efectos de las resoluciones de la SCJN en la acción de inconstitucionalidad, sólo se podrá declarar la invalidez de las normas impugnadas, siempre que fueren aprobadas por una mayoría de cuando menos ocho votos (de entre once ministros que integran el Pleno). Es de reiterar que al mismo tiempo que la Corte tiene encomendadas estas funciones, actúa como tribunal de legalidad cuando resuelve, por ejemplo, las contradicciones de criterios de los tribunales colegiados de circuito o de las propias salas de la Suprema Corte, o cuando ejerce la facultad de atracción. Lo anterior es otra expresión de la mixtura que se presenta en México de elementos característicos de cada una de las dos modalidades típicas de control constitucional a los que me he referido.

La previsión del artículo 105 constitucional no cancela por sí misma la posibilidad de que otros órganos jurisdiccionales sean competentes para ejercer funciones de control, pero está claro que ello tendrá que realizarse por una vía distinta a la acción de inconstitucionalidad. Es decir que, en tanto no esté previsto un dispositivo que así lo proscriba, otros tribunales pueden realizar un control de carácter difuso y concreto. Pero si el quejoso aspira a que se determine la nulidad de la norma que resulte

\footnotetext{
13 “La única vía para plantear la no conformidad de las leyes electorales a la Constitución es la prevista en este artículo", artículo 105, fracción II, párrafo tercero de la Constitución.

${ }^{14}$ Tesis P. /J. 25/99, Semanario Judicial de la Federación y su Gaceta, Novena Época, t. IX, p.255, procedente de la acción de inconstitucionalidad 10/1998, derivada de la acción de inconstitucionalidad 3/2005.
} 
Esta obra forma parte del acervo de la Biblioteca Jurídica Virtual del Instituto de Investigaciones Jurídicas de la UNAM

inconstitucional, sólo la promoción ante la Corte podrá servirle si al final se obtiene la mayoría de ocho o más votos de entre los ministros.

\section{El amparo contra leyes y la sombra}

de la fórmula Otero

Otra de las singularidades del derecho mexicano es que el juicio de amparo no incorpora en su esfera de protección a los derechos político-electorales; de hecho, la ley reglamentaria dispone expresamente que el amparo será improcedente contra las resoluciones o declaraciones de las autoridades competentes en materia electoral. ${ }^{15}$ No obstante, estimamos que analizar la situación del amparo contra leyes es una referencia útil en el estudio de los controles constitucionales en México, sobre todo — para los efectos de este trabajo- en relación con uno de los rasgos que le han sido característicos: la relatividad de las sentencias, es decir, los efectos particulares de las mismas.

El juicio de amparo es una institución jurídica de hondo arraigo histórico en México y es un instrumento dotado de gran amplitud funcional en el control de la regularidad constitucional a través de la protección de los derechos fundamentales. Cerca de un siglo y medio, México fue innovador en la instauración de este juicio, a tal punto que la terminología empleada por primera vez en nuestro país (amparo) ha sido imitada en distintos sistemas jurídicos de habla hispana y en la Declaración Universal de Derechos Humanos (aprobada en 1948 por la Asamblea General de la Organización de las Naciones Unidas), cuyo artículo 80. dispone que toda persona tiene derecho a un recurso efectivo ante los tribunales "que la ampare" contra actos que violen sus derechos fundamentales.

En muchas ocasiones se hace referencia a la institución del amparo como un timbre de orgullo para este país, pero, por lo mismo, a lo largo del tiempo se han presentado muchas resistencias a la evolución de esta figura. Con el paso de los años, paradójica y lamentablemente, México se llegó a convertir en uno de los países más rezagados en la materia. No fue sino hasta la reforma constitucional del 6 de junio de 2011 que se realizaron actualizaciones constitucionales muy importantes en materia de amparo

\footnotetext{
${ }^{15}$ La improcedencia del amparo en materia electoral se establece explícitamente en el artículo 61, fracciones IV y XV de la Ley de Amparo (previo a la nueva legislación en materia de amparo promulgada en el Diario Oficial de la Federación el 2 de abril de 2013, la improcedencia se preveía en la fracción VII del artículo 73).
} 
Esta obra forma parte del acervo de la Biblioteca Jurídica Virtual del Instituto de Investigaciones Jurídicas de la UNAM www.juridicas.unam.mx

(artículos 103 y 107 de la ley fundamental). Antes de ello habían fracasado numerosos intentos para poner al día al amparo mexicano, en aspectos, por ejemplo, como la ampliación del concepto de autoridad para efectos de éste, ensanchar la noción del interés jurídico y generalizar los efectos de las sentencias en determinados casos. ${ }^{16}$

Para contextualizar este punto, debemos decir que uno de los sectores en que se divide el juicio de amparo en México ha sido el "amparo contra leyes", ${ }^{17}$ juicio con el que es posible cuestionar la constitucionalidad de una ley por estimarla atentatoria de derechos fundamentales (excepción hecha de los derechos políticos). Por virtud de la Ilamada fórmula Otero, cuyo origen data de 1847, el efecto de las sentencias de amparo se limita a proteger a las partes litigantes en el caso particular sobre el que versa la queja, sin hacer una declaración general respecto de la ley o acto que la motive. ${ }^{18}$ Este fue uno de aspectos de mayor rezago del amparo mexicano, como lo señalan Fix Zamudio y Ferrer Mac-Gregor:

Debe señalarse que un sector mayoritario de la doctrina mexicana ha apoyado desde hace tiempo la declaración general en el juicio de amparo cuando se impugnan normas legislativas, pero algunos juristas nacionalistas continúan la defensa de la corriente

${ }^{16}$ Un intento memorable para modernizar el amparo mexicano fue el procedimiento que inició la SCJN en noviembre de 1999 con la conformación de una Comisión de Análisis de la regulación del amparo, presidida por el ministro Humberto Román Palacios e integrada por el también ministro Juan Silva Meza y académicos como el doctor Héctor Fix-Zamudio, José Ramón Cossío Díaz y Arturo Zaldívar Lelo de Larrea, entre otros miembros. La Corte también emitió una convocatoria pública a la comunidad jurídica (litigantes, asociaciones de abogados, etcétera) para recibir planteamientos al respecto, misma que tuvo una vigorosa respuesta. Tras un gran esfuerzo, que incluyó amplias discusiones y la realización de once foros de análisis, se arribó a una propuesta de nueva ley de amparo que se entregó al Congreso de la Unión el 30 de abril de 2001. Por desgracia, el texto propuesto no encontró eco en el Poder Legislativo sino hasta la siguiente década.

17 De acuerdo con el tratadista Héctor Fix-Zamudio, el amparo contra leyes conformaba uno de los cinco sectores en que se dividió tradicionalmente esta institución jurídica; los otros: a) el amparo habeas corpus o de la libertad; b) el amparo judicial o amparo-casación; c) el amparo de lo contencioso administrativo, y d) el amparo social agrario. Véase Fix-Zamudio, Héctor, Protección jurídica de los derechos humanos, estudios comparativos, México, Comisión Nacional de Derechos Humanos, 1999, p. 555.

18 Ortiz Mayagoitia, Guillermo, "Control de la constitucionalidad de las leyes electorales en México", en Sistemas de justicia electoral: evaluación y perspectivas, México, Tribunal Electoral del Poder Judicial de la Federación, 1999, pp. 319 y 320. 
Esta obra forma parte del acervo de la Biblioteca Jurídica Virtual del Instituto de Investigaciones Jurídicas de la UNAM www.juridicas.unam.mx

tradicional de los efectos particulares, a los cuales habría que añadir algunos políticos, inclusive legisladores que han señalado reservas para esta innovación, y ambos grupos invocan argumentos decimonónicos totalmente superados como son los relativos a la violación del principio de la división de funciones o poderes, desconociendo la evolución de dicho principio hacia el de separación, equilibrio y colaboración de funciones. ${ }^{19}$

Atendiendo este tipo de reclamos, la fórmula Otero fue suavizada en el "amparo contra leyes", y en la mencionada reforma constitucional de 2011 se incorporó la declaratoria general de inconstitucionalidad, con la cual pueden extinguirse las leyes inconstitucionales, en defensa de la regularidad constitucional.

La regla general sigue presente en el primer párrafo de la fracción segunda del artículo 107 constitucional, en el sentido de que las sentencias que se dicten en los juicios de amparo "sólo se ocuparán de los quejosos que lo hubieren solicitado, limitándose a ampararlos y protegerlos, si procediere, en el caso especial sobre el que verse la demanda". Pero he aquí la excepción en los siguientes párrafos del mencionado precepto constitucional:

Cuando en los juicios de amparo indirecto en revisión se resuelva la inconstitucionalidad de una norma general por segunda ocasión consecutiva, la Suprema Corte de Justicia de la Nación lo informará a la autoridad emisora correspondiente.

Cuando los órganos del Poder Judicial de la Federación establezcan jurisprudencia por reiteración en la cual se determine la inconstitucionalidad de una norma general, la Suprema Corte de Justicia de la Nación lo notificará a la autoridad emisora. Transcurrido el plazo de 90 días naturales sin que se supere el problema de inconstitucionalidad, la Suprema Corte de Justicia de la Nación emitirá, siempre que fuere aprobada por una mayoría de cuando menos ocho votos, la declaratoria general de inconstitucionalidad, en la cual se fijarán sus alcances y condiciones en los términos de la ley reglamentaria.

Lo dispuesto en los dos párrafos anteriores no será aplicable a normas generales en materia tributaria.

Como se aprecia, se trata de una aproximación limitada en el control de constitucionalidad de leyes por la vía del amparo; sin embargo, nos parece una buena noticia que finalmente sea posible la generalización de los efectos de las sentencia de amparo en las que resuelva que una norma se encuentra en conflicto con la carta magna.

${ }^{19}$ Fix-Zamudio, Héctor y Ferrer Mac-Gregor, Eduardo, op. cit., pp. 216 y 217. 
Esta obra forma parte del acervo de la Biblioteca Jurídica Virtual del Instituto de Investigaciones Jurídicas de la UNAM

\section{CONTROL DE CONSTITUCIONALIDAD DE LEYES ELECTORALES}

\section{La jurisdicción electoral}

Rodolfo Terrazas ha definido la justicia constitucional electoral como el sistema de control desarrollado procesalmente en la Constitución general y la ley secundaria, a través de las figuras de acciones, juicios o recursos (medios de impugnación en sentido amplio), que tendrían como fin la reparación del régimen jurídico tanto constitucional como legal para la materia electoral, mediante la invalidación de actos, resoluciones o normas generales contraventoras de dicho régimen jurídico, así como la restitución efectiva y plena de los derechos fundamentales del ciudadano que sean de naturaleza política. $^{20}$

La entidad que guarda el Tribunal Electoral del Poder Judicial de la Federación como tribunal constitucional, especializado en la materia electoral, es consecuente con la evolución democrática que ha tenido México en los últimos lustros. Es un sistema singular en el ámbito del derecho comparado pero que responde a las características propias de nuestra democracia y al desenvolvimiento que de manera vertiginosa ha tenido en el último cuarto de siglo.

La progresión de la justicia electoral inicia con la Ley Federal de Organizaciones Políticas y Procesos Electorales de 1977, en la que se presentaron los primeros visos de judicializar las impugnaciones electorales con recursos de los que conocía la SCJN, mas cuyos fallos no resultaban vinculantes. Con posterioridad, en el Código Electoral de 1986 se creó el Tribunal de lo Contencioso Electoral, mismo que contaba con jurisdicción para resolver los recursos de apelación y de queja; sin embargo, en lo sustantivo, las violaciones que trascendieran al resultado de la elección sólo podrían ser modificadas por los colegios electorales en el Poder Legislativo, lo cual seguía siendo un sistema mixto donde la calificación por órganos políticos se combinó con la protección jurisdiccional. ${ }^{21}$

\footnotetext{
${ }^{20}$ Terrazas Salgado, Rodolfo, Introducción al estudio de la justicia constitucional electoral en México, México, Ángel Editor, 2006, p. 91.

${ }^{21}$ Castillo González, Leonel, Reflexiones temáticas sobre derecho electoral, México, Tribunal Electoral del Poder Judicial de la Federación, 2006, p. 127.
} 
Esta obra forma parte del acervo de la Biblioteca Jurídica Virtual del Instituto de Investigaciones Jurídicas de la UNAM www.juridicas.unam.mx

Mediante las reformas de 1989-1990 se creó el Tribunal Federal Electoral, el cual tuvo atribuciones jurídicas de más amplio alcance. Esto se complementó con las reformas de 1993, que al contemplar la desaparición de la autocalificación, amplió las facultades del Instituto Federal Electoral para declarar la validez de las elecciones y reconoció ya desde entonces al Tribunal Federal Electoral como la máxima autoridad jurisdiccional en la materia.

Con la reforma de 1996 se instauró un sistema de medios de impugnación para el control constitucional y legal de los actos, y resoluciones electorales, ya fueran federales o locales. Aquel decreto de reformas ordenó a las legislaturas locales establecer un sistema de justicia electoral en la respectiva entidad federativa, acorde con el sistema nacional. En 1996 se da también un paso trascendental al fijarse la incorporación del Tribunal Electoral al Poder Judicial Federal y, en particular, el control para la defensa de derechos constitucionales de naturaleza político-electoral a través de un juicio particularmente creado para el efecto. ${ }^{22}$

\section{Periodo 1996 a 2002. Control difuso por el TEPJF}

El artículo 41 constitucional, en su base VI, dispone que "para garantizar los principios de constitucionalidad y legalidad de los actos, y resoluciones electorales, se establecerá un sistema de medios de impugnación", mismo que dará definitividad a las distintas etapas de los procesos electorales y garantizará la protección de los derechos políticos de los ciudadanos de votar, ser votados y de asociación, en los términos del artículo 99 de la propia carta fundamental.

Con base en lo anterior, desde 1996 hasta 2002, el TEPJF realizó un control de tipo difuso, en términos similares a la función que realizan los tribunales colegiados de circuito, y que no constituye menoscabo alguno al ámbito de control que es propio de la SCJN. Así fue que el TEPJF, dentro de su ámbito de competencia, examinó los actos y resoluciones que fueron emitidos con base en una norma cuya constitucionalidad estuviera en tela de juicio. Lo anterior lo efectuó simplemente no aplicando la norma

22 Ibidem, p. 128. A este al respecto, Leonel Castillo (expresidente del TEPJF) hace notar que la Comisión Interamericana de Derechos Humanos hizo un reconocimiento de los avances alcanzados en México, al emitir un informe especial sobre la situación de los derechos humanos. En lo relativo a los derechos políticos, destacó los trascendentes avances y enfatizó como uno de los logros sustanciales de la reforma de 1996 la integración del Tribunal Electoral del Poder Judicial de la Federación. 
Esta obra forma parte del acervo de la Biblioteca Jurídica Virtual del Instituto de Investigaciones Jurídicas de la UNAM www.juridicas.unam.mx

electoral que se opusiera a algún dispositivo de la Constitución, pues ya hemos visto que su invalidación (efectos generales) sólo podría dictarla la Corte al resolver una acción de inconstitucionalidad. Orozco Henríquez nos da un dato interesante:

Con anterioridad (al criterio de la SCJN en 2002) la Sala Superior (del TEPJF) inaplicó en 33 casos concretos alguna norma legal por considerarla incidentalmente inconstitucional, la mayoría de los cuales versaron sobre el no otorgamiento de financiamiento público a partidos políticos de nueva creación, la exigencia del escrito de protesta ante la autoridad administrativa como requisito de procedibilidad del juicio de inconformidad contra resultados electorales, y la exigencia a partidos políticos de haber registrado candidatos para ayuntamiento en cierto municipio para tener derecho a la asignación de regidores de representación proporcional en uno distinto. ${ }^{23}$

Con base en lo que ya hemos analizado, es muy importante subrayar que este sistema de control se constituía en la única posibilidad del ciudadano común para acceder a la justicia constitucional en la materia electoral cuando fuera afectado por una ley inconstitucional, ya que, por una parte, el juicio de amparo es improcedente contra leyes electorales y, por otra, los ciudadanos carecen de legitimación activa para promover una acción de inconstitucionalidad.

\section{Periodo de 2002 a 2007. Control}

\section{concentrado por la SCJN}

Al resolverse el expediente de contradicción de tesis identificado con la clave 2/2000-PL, el 23 de mayo de 2002 la SCJN determinó la falta de competencia del TEPJF para pronunciarse sobre la inconstitucionalidad de leyes. ${ }^{24}$ La Corte planteó en dicha resolución su propia exclusividad para conocer de acciones de inconstitucionalidad, con lo cual nadie tenía objeciones. En efecto, esa era y sigue siendo su facultad exclusiva. Tan es así, que la Ley Reglamentaria de las Fracciones I y II del artículo 105 de la Constitución establece las modalidades especiales de la acción de inconstitucionalidad en lo relativo a leyes electorales, abreviándose los plazos y señalándose que en estos casos el ministro

\footnotetext{
23 Orozco Henríquez, J. Jesús, “Jurisprudencia electoral y reforma constitucional y legal”, en Constitución, democracia y elecciones. La reforma que viene, México, UNAM, 2007, p. 35.

24 La tesis 23/2002 señalaba en su rubro: Tribunal Electoral del Poder Judicial de la Federación. Carece de COMPETENCIA PARA PRONUNCIARSE SOBRE INCONSTITUCIONALIDAD DE LEYES.
} 
Esta obra forma parte del acervo de la Biblioteca Jurídica Virtual del Instituto de Investigaciones Jurídicas de la UNAM

instructor podrá solicitar opinión a la Sala Superior del TEPJF. ${ }^{25}$

El problema fue que la resolución de la Corte dejó impedido al TEPJF para pronunciarse sobre actos o resoluciones que se fundamentaran en una norma inconstitucional, pese a que el sistema de medios de impugnación en materia electoral tiene por objeto garantizar que todos esos actos y resoluciones de autoridades se sujeten invariablemente a los principios de constitucionalidad y legalidad. De este modo, el ciudadano quedó incapacitado para impugnar por sí mismo la constitucionalidad de una ley electoral.

En la práctica, las consecuencias no se hicieron esperar. El asunto más emblemático fue el caso Castañeda (amparo en revisión 743/2005), en el que un ciudadano _Jorge Castañeda Gutman- impugnó la omisión legislativa en materia de candidaturas independientes, y diversos artículos del Código Federal de Instituciones y Procedimientos Electorales (Cofipe). A mayor precisión, la mayoría del Pleno de la SCJN confirmó el sobreseimiento decretado por el juez de distrito, por lo que se juzgó improcedente el juicio de amparo aduciéndose que la única vía única para impugnar leyes electorales era la acción de inconstitucionalidad. La minoría de ministros que se oponía a este criterio, pensaba que impedir al quejoso cuestionar la constitucionalidad de una ley trastocaría el derecho a ser votado y lesionaría el acceso a la justicia. Por lo que, tenían toda la razón, ya que en el estado anterior de cosas, la Corte hubiera podido remitir sin problema el asunto al TEPJF para que el quejoso no quedara en estado de indefensión.

Con posterioridad dicho ciudadano (Castañeda Gutman) optó por acudir a las instancias internacionales, mismas que conocieron del asunto y por fin, en agosto de 2008, se presentó el desenlace que ya se esperaba. La Corte Interamericana de Derechos Humanos declaró que México, en efecto, violó los derechos humanos del impugnante. Reproducimos aquí parte del pronunciamiento:

131. Dado que el recurso de amparo no resulta procedente en materia electoral, la naturaleza extraordinaria de la acción de inconstitucionalidad y la inaccesibilidad e inefectividad del juicio de protección para impugnar la falta de conformidad de una ley con la Constitución, en la época de los hechos del presente caso, no había en México recurso

\footnotetext{
${ }^{25}$ Artículo 68, párrafo segundo, de la Ley Reglamentaria de las Fracciones I y II del artículo 105 de la Constitución Política de los Estados Unidos Mexicanos.
} 
Esta obra forma parte del acervo de la Biblioteca Jurídica Virtual del Instituto de Investigaciones Jurídicas de la UNAM www.juridicas.unam.mx

efectivo alguno que posibilitara a las personas cuestionar la regulación legal del derecho político a ser elegido previsto en la Constitución Política y en la Convención Americana. (...)

133. En el presente caso, la inexistencia de un recurso efectivo constituyó una violación de la Convención por el Estado Parte, y un incumplimiento de su deber de adoptar disposiciones de derecho interno para hacer efectivos los derechos establecidos en la Convención, en los términos del artículo 25 de la Convención Americana de Derechos humanos, en relación con los artículos 1.1 y 2 de dicho tratado. ${ }^{26}$

Se debió tener claro desde un principio que, si un acto o resolución electoral se funda en una ley incompatible con la carta magna, significa que no se sujeta a los principios de constitucionalidad y legalidad. Por eso es que, como hemos dicho, antes del criterio emitido en el expediente de contradicción de tesis 2/2000-PL, el Tribunal Electoral podía ejercer un control difuso. Pero desde mayo de 2002 (y hasta la reforma electoral de 2007), quedó cerrada esta puerta para impugnar la no conformidad de una ley electoral con la Constitución.

Como bien lo señala Jesús Orozco Henríquez, la autoridad jurisdiccional se vio obligada a aplicar normas, aunque las juzgara inconstitucionales, o a convalidar actos que tuvieran fundamento en tales disposiciones:

Esta circunstancia contravino el derecho a la tutela jurisdiccional completa y efectiva (artículo 17 constitucional) y el derecho de toda persona a disponer de un recurso judicial efectivo ante un tribunal competente, imparcial, independiente y preestablecido conforme a lo previsto en los artículos $8^{\circ}$. del Pacto de San José y 14 del Pacto Internacional de Derechos Civiles y Políticos. La decisión de la SCJN produjo una “disfuncionalidad del sistema". ${ }^{27}$

José Ramón Cossío se refirió a esta circunstancia como "el indebido monopolio constitucional-electoral de la Suprema Corte de Justicia". ${ }^{28}$ Otros doctrinarios señalaron que el control concreto debería ser ejercido por el Tribunal Electoral, ya que no supone

\footnotetext{
${ }^{26}$ La ministra de la SCJN, Margarita Beatriz Luna Ramos, hace un detenido estudio del caso Castañeda en su ensayo "El control constitucional de las leyes a cargo del TEPJF" en Córdova Vianello, Lorenzo y Salazar, Pedro (coords.), Estudios sobre la reforma electoral 2007: hacia un nuevo modelo, México, Tribunal Electoral del Poder Judicial de la Federación, 2008, pp. 442-450.

27 Orozco Henríquez, J. Jesús, op. cit., p. 36.

${ }^{28}$ Cossío Díaz, José Ramón, op. cit., pp. 35-39.
} 
Esta obra forma parte del acervo de la Biblioteca Jurídica Virtual del Instituto de Investigaciones Jurídicas de la UNAM

pronunciarse sobre la inconstitucionalidad de una norma electoral general sino sobre los actos de aplicación concretos de la misma. En particular, Lorenzo Córdova y Pedro Salazar consideraron que la resolución de la Suprema Corte era equívoca en tanto confundía la naturaleza del control de constitucionalidad, “lo que tiene como consecuencia, entre otras cosas, hacer nugatorio el sistema garantista en materia electoral contemplado en la Constitución". ${ }^{29}$

Ya se proponía desde entonces la conveniencia de explicitar en la Constitución la competencia del TEPJF para realizar un control concreto de la constitucionalidad de leyes electorales, y zanjar así la aparente disputa de competencias o -mejor dicho- la "guerra de las cortes", como en su oportunidad le denominó a ese episodio César Astudillo. $^{30}$

\section{La salida encontrada por el TEPJF}

Ante la grave circunstancia ya descrita, la Sala Superior del Tribunal Electoral, en su actual integración (configurada a finales de 2006) optó por ampliar, en el ámbito de su competencia, los alcances del juicio para la protección de los derechos políticoelectorales del ciudadano, a partir de una interpretación extensiva de los derechos político-electorales de los ciudadanos.

El producto fue lo que se denominó un control judicial de leyes y actos conforme a los tratados internacionales. Esto quiere decir que ante la prohibición de pronunciarse sobre la inconstitucionalidad de leyes electorales, la sala realizó una "interpretación conforme" de la ley con los tratados internacionales, ya que —claro está- el juez debe garantizar la eficacia de ambas normas. ${ }^{31}$ Por lo que, el TEPJF no ejerció un control de constitucionalidad de la ley para inaplicarla (porque no estaba autorizado), sino uno "de convencionalidad" de actos de aplicación de leyes que se encontraran en conflicto con instrumentos de derecho internacional (tratados y convenciones).

\footnotetext{
${ }^{29}$ Córdova Vianello, Lorenzo y Salazar, Pedro (coords.), Constitución, democracia y elecciones. La reforma que viene, México, UNAM, 2007, pp. 176 y ss.

${ }^{30}$ Astudillo, César, “La guerra de las cortes”, Revista Nexos, México, vol. XXX, núm. 366, 2008, pp. 58-60.

${ }^{31}$ Es de recordar que el 13 de febrero de 2007, el Pleno de la SCJN había acentuado el criterio por el que los tratados internacionales se encontraban en un rango de jerarquía normativa inmediatamente inferior al de la Constitución Política de los Estados Unidos Mexicanos, y superior al de las leyes federales y de las entidades federativas.
} 
Esta obra forma parte del acervo de la Biblioteca Jurídica Virtual del Instituto de Investigaciones Jurídicas de la UNAM

Un ilustrativo ejemplo fue lo resuelto por la Sala Superior en el caso Hank Rohn, mismo en el que se impugnó la coloquialmente llamada ley antichapulín. Ésta fue una norma incorporada a la Constitución del estado de Baja California en 2002, que hacía inelegible a quien ocupara un cargo de elección para postularse a otro distinto antes de completar el periodo para el cual había sido electo. El propósito del legislador era evitar que los políticos utilizaran su cargo público para "brincar" a otro, tal como lo haría un genuino chapulín o saltamontes.

En ejercicio del "control de convencionalidad" la "ley antichapulín" fue inaplicada por el TEPJF ${ }^{32}$ al estimar que ésta era contraria a tratados internacionales, ya que restringía derechos políticos reconocidos en la Convención Americana sobre Derechos Humanos, suscrita y ratificada por el Estado mexicano. El punto a destacar es que la norma bajacaliforniana era desde luego también contraria a la Constitución (los límites a un derecho constitucional como el de ser votado tendrían que consignarse desde la propia carta magna y no por un cuerpo normativo de inferior jerarquía normativa). El problema era que el Tribunal Electoral carecía en ese entonces de la facultad de control de constitucionalidad de leyes electorales. ${ }^{33}$

Por estas razones creemos que ese peculiar método de control, empleado en su momento por la Sala Superior, es digno de encomio. La gravedad de la situación no dejaba lugar para la ortodoxia: se estaba en un escenario casi surrealista en el que el Tribunal Electoral tenía prohibido hacer prevalecer la norma superior sobre la inferior y los ciudadanos carecían de todo recurso, hallándose en estado de indefensión. En ese extremo fue que - contra todo pronóstico- el TEPJF encontró una salida al callejón mediante el "control de convencionalidad", mismo que operó, tanto como fue posible, en defensa de los derechos políticos de los ciudadanos y de la garantía a la tutela judicial efectiva.

\section{REFORMA ELECTORAL 2007-2008}

El 13 de noviembre de 2007 fue publicada en el Diario Oficial de la Federación la reforma

\footnotetext{
32 Sentencia recaída al expediente SUP-JDC-695/2007 en el llamado caso Hank. El entonces presidente municipal de Tijuana, Baja California, Jorge Hank Rohn, aspiraba a la gubernatura de Baja California pero la Constitución local le impedía postularse antes de haber completado su periodo para el que había sido electo.

33 Véase Duque Roquero, Roberto, "Reelección de diputados locales y ayuntamientos", Revista Folios, México, núm. 18, 2010, p. 18.
} 
Esta obra forma parte del acervo de la Biblioteca Jurídica Virtual del Instituto de Investigaciones Jurídicas de la UNAM

del artículo 99 constitucional, entre otros preceptos. En su párrafo sexto estableció lo siguiente:

Artículo 99, párrafo sexto: sin perjuicio de lo dispuesto por el artículo 105 de esta Constitución, las salas del Tribunal Electoral podrán resolver la no aplicación de leyes sobre la materia electoral contrarias a la presente Constitución. Las resoluciones que se dicten en el ejercicio de esta facultad se limitarán al caso concreto sobre el que verse el juicio. En tales casos la Sala Superior informará a la Suprema Corte de Justicia de la Nación.

Posteriormente la Ley Orgánica del Poder Judicial de la Federación (por modificación publicada en el Diario Oficial de la Federación el 1 de julio de 2008) estableció de manera expresa la competencia tanto de la Sala Superior como de las salas regionales para resolver la no aplicación, en casos concretos, de leyes electorales contrarias a la Constitución (artículos 189 y 195, respectivamente). ${ }^{34}$ También se estableció la atribución de los presidentes de las salas regionales competentes para enviar a la Sala Superior los informes relativos a dicha inaplicación.

De este modo, por primera vez se reconoció una competencia expresa al TEPJF para ejercer control de la constitucionalidad de las leyes electorales, con lo que quedó sepultado el multicitado criterio de la Corte que había imperado a partir de 2002 (contradicción de tesis 2/2000-PL), cuyos defectos ya han sido suficientemente descritos. Por lo que, quedó disipada cualquier duda sobre la jurisdicción constitucional del Tribunal Electoral.

En referencia al contexto de esta reforma, cabe resaltar que antes de su aprobación se habían analizado distintas posibilidades para devolver el control de la constitucionalidad de leyes electorales al TEPJF. Una opción consistía en que, cuando se planteara un caso de esta naturaleza al Tribunal Electoral, se contemplara la promoción de la respectiva cuestión de inconstitucionalidad ante la SCJN de manera previa (como en el modelo español) o como un ulterior recurso una vez que el Tribunal inaplicara la norma en algún caso concreto. No obstante, se reparó en que estas hipótesis podrían haber presentado dificultades funcionales u operativas, dado que los plazos electorales

\footnotetext{
34 En el artículo 195 se excluye de esta competencia a la Sala Regional Especializada del TEPJF, creada por virtud de la reforma electoral 2014.
} 
Esta obra forma parte del acervo de la Biblioteca Jurídica Virtual del Instituto de Investigaciones Jurídicas de la UNAM www.juridicas.unam.mx

son reducidos. ${ }^{35}$

Otra opción analizada proponía la integración de una "Sala Electoral" de la Suprema Corte de Justicia. Sin embargo, no concordamos con dicha propuesta, pues soslayaba los rasgos distintivos del sistema electoral mexicano (derivados del rápido tránsito que existió en México de un sistema de partido hegemónico a uno de competencia electoral pluripartidaria). El resultado de tal evolución es que en México, la materia electoral ha adquirido un carácter sumamente particular, especializado y técnico, en el que se exige, entre otras cosas, la autonomía de las autoridades electorales. Este tipo de circunstancias son justamente las que llevaron a que el Poder reformador de la Constitución definiera la naturaleza del TEPJF hasta lo que tenemos hoy: un órgano especializado como autoridad máxima en la materia (salvo -como ya sabemos- en acciones de inconstitucionalidad), y cuyas resoluciones son definitivas e inatacables.

Al final del día, la reforma constitucional electoral de 2007 preservó y concilió las dos realidades ya existentes: por un lado, el artículo 105 de la Constitución que desde 1994 estableció la competencia de la Suprema Corte para conocer de las acciones de inconstitucionalidad como medio de control constitucional y resolver las contradicciones entre una norma general y la propia ley fundamental; por la otra parte, desde 1996 se reconoce una jurisdicción especializada en la materia en la que el TEPJF se erige como la máxima autoridad jurisdiccional para resolver las impugnaciones de carácter electoral.

Por virtud de la reforma constitucional de 2007, está claro que el control constitucional en materia electoral se integra con la acción de inconstitucionalidad y con los medios de impugnación electorales.

\section{INAPLICACIÓN DE NORMAS ELECTORALES POR EL TRIBUNAL ELECTORALDEL PODER JUDICIAL DE LA FEDERACIÓN}

En la práctica, el TEPJF ha ejercido ya el control constitucional conferido por la reforma de 2007 en diversas ocasiones, determinando la no aplicación de leyes en materia electoral por considerarlas contrarias a la Constitución. La reforma ha propiciado que tengamos un estado de cosas similar al que existía antes del multicitado criterio de la SCJN (contradicción de tesis 2/2000-PL) aunque actualmente también las Salas

\footnotetext{
${ }^{35}$ Se recomienda el puntual análisis que el doctor Orozco Henríquez realiza al respecto, Orozco Henríquez, J. Jesús, op. cit., pp. 36 y 37.
} 
Esta obra forma parte del acervo de la Biblioteca Jurídica Virtual del Instituto de Investigaciones Jurídicas de la UNAM www.juridicas.unam.mx

Regionales del TEPJF — que son de carácter permanente- hacen pronunciamientos de inaplicación de leyes (antes de la referida reforma, las salas se instalaban sólo durante los procesos electorales federales).

Casos de inaplicación de leyes por el TEPJF a partir de la reforma de $2007^{36}$

\begin{tabular}{|c|c|c|c|}
\hline Núm. & $\begin{array}{l}\text { Tipo de juicio } y \\
\text { expediente }\end{array}$ & $\begin{array}{l}\text { Disposición cuya inaplicación se } \\
\text { determinó }\end{array}$ & $\begin{array}{l}\text { Fecha de la } \\
\text { resolución }\end{array}$ \\
\hline 1 & $\begin{array}{l}\text { Juicios de revisión } \\
\text { constitucional } \\
\text { electoral SUP-JRC- } \\
494 / 2007 \text { y } \\
\text { SUP-JRC- } \\
496 / 2007\end{array}$ & $\begin{array}{l}\text { Artículo } 288 \text { del Código Electoral del } \\
\text { Estado de Aguascalientes. (Exigencia } \\
\text { de escrito de protesta por los } \\
\text { resultados contenidos en el acta de } \\
\text { escrutinio y cómputo de la casilla). }\end{array}$ & $\begin{array}{l}19 \text { de } \\
\text { diciembre } \\
\text { de } 2007\end{array}$ \\
\hline 2 & $\begin{array}{l}\text { Juicios de revisión } \\
\text { constitucional } \\
\text { electoral SUP-JRC- } \\
105 / 2008 \text { y } \\
107 / 2008\end{array}$ & $\begin{array}{l}\text { Artículo segundo transitorio del } \\
\text { Estatuto de Gobierno del Distrito } \\
\text { Federal. (Nombramiento de } \\
\text { consejeros electorales locales). }\end{array}$ & $\begin{array}{l}11 \text { de junio } \\
\text { de } 2008\end{array}$ \\
\hline 3 & 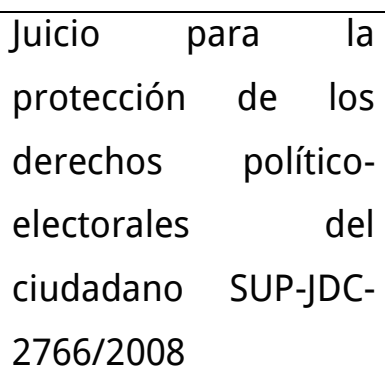 & $\begin{array}{l}\text { Artículo 154, párrafo } 8 \text { de la Ley } \\
\text { Electoral del Estado de San Luis } \\
\text { Potosí. (Derecho de reunión en actos } \\
\text { de precampaña electoral). }\end{array}$ & $\begin{array}{l}29 \text { de } \\
\text { octubre de } \\
2008\end{array}$ \\
\hline 4 & $\begin{array}{lr}\text { Juicio para } & \text { la } \\
\text { protección } & \text { de los } \\
\text { derechos } & \text { político- } \\
\text { electorales } & \text { del } \\
\text { ciudadano } & \text { SG-JDC- } \\
73 / 2009 & \end{array}$ & $\begin{array}{l}\text { Artículo 132, fracción IV, de la } \\
\text { Constitución Política del Estado Libre } \\
\text { y Soberano de Sonora. }\end{array}$ & $\begin{array}{l}26 \text { de marzo } \\
\text { del } 2009\end{array}$ \\
\hline 5 & Juicio de revisión & Artículo 90, párrafo 3, fracciones I, II, & 8 de abril de \\
\hline
\end{tabular}

\footnotetext{
${ }^{36}$ Fuente: Tribunal Electoral del Poder Judicial de la Federación, información actualizada al 10 de diciembre de 2014
} 
Esta obra forma parte del acervo de la Biblioteca Jurídica Virtual del Instituto de Investigaciones Jurídicas de la UNAM www.juridicas.unam.mx

DOI: http://dx_doil.org/10.22201/iij.24487910e_2015.7.10086

\begin{tabular}{|c|c|c|c|}
\hline & $\begin{array}{l}\text { constitucional } \\
\text { electoral SUP-JRC- } \\
10 / 2009\end{array}$ & $\begin{array}{l}\text { III, inciso a), así como la fracción IV y } \\
\text { el párrafo 4, del Código Electoral y de } \\
\text { Participación Ciudadana de Jalisco. } \\
\text { (Límites de financiamiento privado a } \\
\text { partidos políticos). }\end{array}$ & 2009 \\
\hline 6 & $\begin{array}{lrr}\text { Juicios } & \text { para } & \text { la } \\
\text { protección } & \text { de } & \text { los } \\
\text { derechos } & \text { político- } \\
\text { electorales } & \text { del } \\
\text { ciudadano } & \text { SUP-JDC- } \\
31 / 2009 & \text { A } & \text { SUP-JDC- } \\
37 / 2009 & & \\
\end{array}$ & $\begin{array}{l}\text { Artículo cuarto transitorio del } \\
\text { Decreto } 149 \text { emitido por la LX } \\
\text { Legislatura del Congreso del Estado } \\
\text { de Aguascalientes. (Nombramiento } \\
\text { de consejeros electorales locales). }\end{array}$ & $\begin{array}{l}8 \text { de abril de } \\
2009\end{array}$ \\
\hline 7 & $\begin{array}{l}\text { Juicio de revisión } \\
\text { constitucional } \\
\text { electoral SUP-JRC- } \\
27 / 2009\end{array}$ & $\begin{array}{l}\text { Artículo 274, fracción II, último } \\
\text { párrafo, del Código Electoral del } \\
\text { Estado de Colima. (Contabilización de } \\
\text { votos por candidaturas comunes). }\end{array}$ & $\begin{array}{l}20 \text { de mayo } \\
\text { de } 2009\end{array}$ \\
\hline 8 & $\begin{array}{lrr}\text { Juicio } & \text { para } & \text { la } \\
\text { protección } & \text { de } & \text { los } \\
\text { derechos } & \text { político- } \\
\text { electorales } & \text { del } \\
\text { ciudadano } & \text { SM-JDC- } \\
339 / 2009 & & \end{array}$ & $\begin{array}{l}\text { Artículo } 11 \text { de la Ley Orgánica } \\
\text { Municipal de Querétaro. }\end{array}$ & $\begin{array}{l}30 \text { de junio } \\
\text { de } 2009\end{array}$ \\
\hline 9 & $\begin{array}{l}\text { Juicio de revisión } \\
\text { constitucional } \\
\text { electoral SUP-JCR- } \\
10 / 2010\end{array}$ & $\begin{array}{l}\text { Última parte del artículo } 62 \text { de la Ley } \\
\text { Orgánica del Instituto Electoral de } \\
\text { Quintana Roo. (Residencia distrital } \\
\text { como requisito de elegibilidad en la } \\
\text { integración de consejos distritales). }\end{array}$ & $\begin{array}{l}5 \text { de marzo } \\
\text { de } 2010\end{array}$ \\
\hline 10 & $\begin{array}{lrr}\text { Juicio } & \text { para } & \text { la } \\
\text { protección } & \text { de } & \text { los } \\
\text { derechos } & \text { político- } \\
\text { electorales } & \text { del } \\
\text { ciudadano } & \text { SUP-JDC- } \\
94 / 2010 & & \end{array}$ & $\begin{array}{l}\text { Artículo 276, párrafo quinto de la Ley } \\
\text { Electoral de Quintana Roo. (Facultad } \\
\text { de los partidos políticos para } \\
\text { presentar denuncias de hechos). }\end{array}$ & $\begin{array}{l}1 \text { de junio } \\
\text { de } 2010\end{array}$ \\
\hline
\end{tabular}


Esta obra forma parte del acervo de la Biblioteca Jurídica Virtual del Instituto de Investigaciones Jurídicas de la UNAM www.juridicas.unam.mx

DOI: http://dx_doil.org/10.22201/ijj.24487910e_2015.7.10086

\begin{tabular}{|c|c|c|c|}
\hline 11 & $\begin{array}{lrr}\text { Juicio para } & \text { la } \\
\text { protección } & \text { de } & \text { los } \\
\text { derechos } & \text { político- } \\
\text { electorales } & \text { del } \\
\text { ciudadano } & \text { SG-JDC- } \\
29 / 2010 & \end{array}$ & $\begin{array}{l}\text { Última parte del párrafo } 6 \text {, de la } \\
\text { fracción I, del artículo } 126 \text { de la } \\
\text { Constitución Política del Estado Libre } \\
\text { y Soberano de Chihuahua. }\end{array}$ & $\begin{array}{l}8 \text { de junio } \\
\text { de } 2010\end{array}$ \\
\hline 12 & $\begin{array}{l}\text { Asunto General SUP- } \\
\text { AG-26/2010 }\end{array}$ & $\begin{array}{l}\text { Artículo } 146 \text { de la Ley Electoral de } \\
\text { Quintana Roo. (Prohibición para } \\
\text { publicar o difundir resultados de } \\
\text { encuestas o sondeos de opinión). }\end{array}$ & $\begin{array}{l}9 \text { de junio } \\
\text { de } 2010\end{array}$ \\
\hline 13 & $\begin{array}{l}\text { Juicio de revisión } \\
\text { constitucional } \\
\text { electoral SG-JRC- } \\
38 / 2010\end{array}$ & $\begin{array}{l}\text { Última parte del párrafo } 6 \text {, de la } \\
\text { fracción I, del artículo 126, de la } \\
\text { Constitución Política del Estado Libre } \\
\text { y Soberano de Chihuahua. }\end{array}$ & $\begin{array}{l}24 \text { de junio } \\
\text { de } 2010\end{array}$ \\
\hline 14 & $\begin{array}{l}\text { Juicio de revisión } \\
\text { constitucional } \\
\text { electoral SUP-JRC- } \\
112 / 2010\end{array}$ & $\begin{array}{l}\text { Segundo párrafo, del artículo } 265 \text { del } \\
\text { Código Electoral del Distrito Federal, } \\
\text { inconstitucionalidad, exclusivamente } \\
\text { por lo que se refiere a la prohibición } \\
\text { a los partidos políticos, coaliciones y } \\
\text { candidatos, de utilizar, en beneficio } \\
\text { propio, la realización de obras } \\
\text { públicas o programas de gobierno. }\end{array}$ & $\begin{array}{l}1 \quad \text { de } \\
\text { septiembre } \\
\text { de } 2010\end{array}$ \\
\hline 15 & 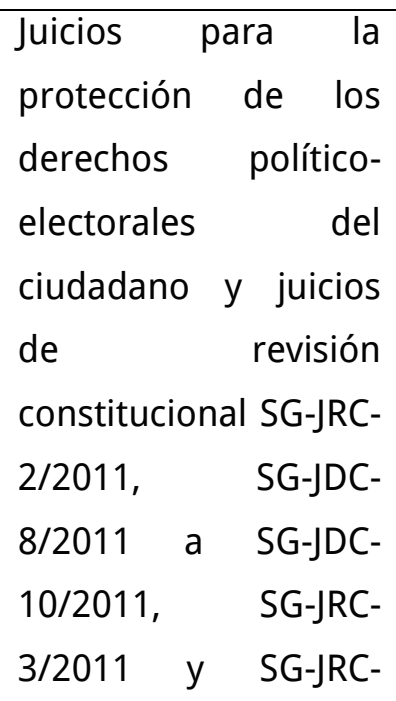 & $\begin{array}{l}\text { Artículo 261, fracción III; 263, } \\
\text { fracción II y III y } 264 \text { de la Ley Estatal } \\
\text { Electoral de Baja California Sur. }\end{array}$ & $\begin{array}{l}9 \text { de marzo } \\
\text { de } 2011\end{array}$ \\
\hline
\end{tabular}


Esta obra forma parte del acervo de la Biblioteca Jurídica Virtual del Instituto de Investigaciones Jurídicas de la UNAM www.juridicas.unam.mx

DOI: http://dx_doil.org/10.22201/ijj.24487910e_2015.7.10086

\begin{tabular}{|c|c|c|c|}
\hline & $4 / 2011$ & & \\
\hline 16 & $\begin{array}{l}\text { Juicio de revisión } \\
\text { constitucional } \\
\text { electoral SUP-JRC- } \\
64 / 2011\end{array}$ & $\begin{array}{l}\text { Segundo párrafo del artículo } 265 \text { del } \\
\text { Código Electoral del Distrito Federal. } \\
\text { (Prohibición a los partidos políticos, } \\
\text { coaliciones y candidatos, de } \\
\text { adjudicarse o utilizar, en beneficio } \\
\text { propio, la realización de obras } \\
\text { públicas o programas de gobierno). }\end{array}$ & $\begin{array}{l}19 \text { de abril } \\
\text { de } 2011\end{array}$ \\
\hline 17 & 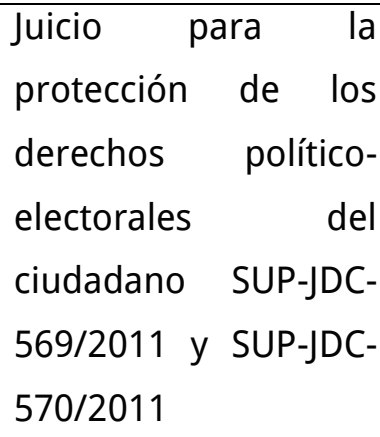 & $\begin{array}{l}\text { Artículo 78, in fine, de la Ley Orgánica } \\
\text { del Poder Legislativo del Estado de } \\
\text { Querétaro. (Abstenciones de voto de } \\
\text { diputados que se suman a la } \\
\text { mayoría). }\end{array}$ & $\begin{array}{l}27 \text { de abril } \\
\text { de } 2011\end{array}$ \\
\hline 18 & $\begin{array}{l}\text { Juicios de protección } \\
\text { de los derechos } \\
\text { político-electorales } \\
\text { del ciudadano SG- } \\
\text { JDC-787/2011 y SG- } \\
\text { JDC-795/2011 }\end{array}$ & $\begin{array}{l}\text { Artículo 209, fracción III, inciso e), } \\
\text { segundo párrafo de la Ley Electoral } \\
\text { del Estado de Nayarit. }\end{array}$ & $\begin{array}{ll}13 & \text { de } \\
\text { agosto de } \\
2011\end{array}$ \\
\hline 19 & 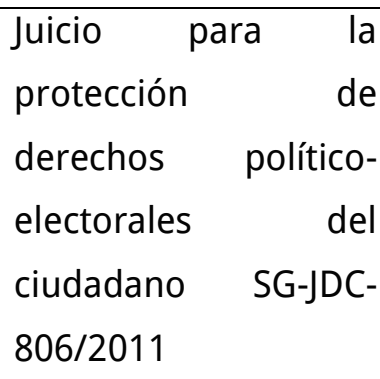 & $\begin{array}{l}\text { Artículo 202, fracción I, de la Ley } \\
\text { Electoral del Estado de Nayarit. }\end{array}$ & $\begin{array}{l}7 \quad \text { de } \\
\text { septiembre } \\
\text { del } 2011\end{array}$ \\
\hline 20 & 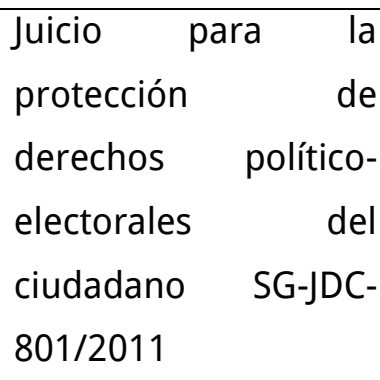 & $\begin{array}{l}\text { Artículo 202, fracción I, de la Ley } \\
\text { Electoral del Estado de Nayarit. }\end{array}$ & $\begin{array}{l}7 \quad \text { de } \\
\text { septiembre } \\
\text { del } 2011\end{array}$ \\
\hline
\end{tabular}


Esta obra forma parte del acervo de la Biblioteca Jurídica Virtual del Instituto de Investigaciones Jurídicas de la UNAM www.juridicas.unam.mx

DOI: http://dx_doï.org/10.22201/ijj.24487910en2015.7.10086

\begin{tabular}{|c|c|c|c|}
\hline 21 & $\begin{array}{lrr}\text { Juicio } & \text { para } & \text { la } \\
\text { protección } & \text { de } & \text { los } \\
\text { derechos } & \text { político- } \\
\text { electorales } & \text { del } \\
\text { ciudadano } & \text { SUP-JDC- } \\
10805 / 2011 & \end{array}$ & $\begin{array}{l}\text { Artículo } 366 \text { del Código Electoral del } \\
\text { Estado de Sonora. (Procedimiento de } \\
\text { remoción de consejeros electorales } \\
\text { locales). }\end{array}$ & $\begin{array}{ll}19 & d e \\
\text { octubre } & \text { de } \\
2011 & \end{array}$ \\
\hline 22 & $\begin{array}{lrr}\text { Juicios } & \text { para } & \text { la } \\
\text { protección } & \text { de } & \text { los } \\
\text { derechos } & \text { político- } \\
\text { electorales } & & \text { del } \\
\text { ciudadano } & \text { ST } & \text {-JDC- } \\
462 / 2011 ; & \text { ST-JDC- } \\
463 / 2011 \text { y juicio de } \\
\text { revisión } \\
\begin{array}{ll}\text { constitucional } & \text { ST-JRC- } \\
93 / 2011 & \end{array}\end{array}$ & $\begin{array}{l}\text { Artículo } 197 \text { del Código Electoral del } \\
\text { Estado de Michoacán. }\end{array}$ & $\begin{array}{l}6 \text { de } \\
\text { diciembre } \\
\text { de } 2011\end{array}$ \\
\hline 23 & $\begin{array}{lrr}\text { Juicio } & \text { para } & \text { la } \\
\text { protección } & \text { de } & \text { los } \\
\text { derechos } & \text { político- } \\
\text { electorales } & & \text { del } \\
\text { ciudadano } & \text { ST } & \text {-JDC- } \\
464 / 2011 \text { y juicio de } \\
\text { revisión } \\
\text { constitucional ST -JRC- } \\
95 / 2011\end{array}$ & $\begin{array}{l}\text { Artículo } 197 \text { del Código Electoral del } \\
\text { Estado de Michoacán. }\end{array}$ & $\begin{array}{l}16 \text { de } \\
\text { diciembre } \\
\text { de } 2011\end{array}$ \\
\hline 24 & 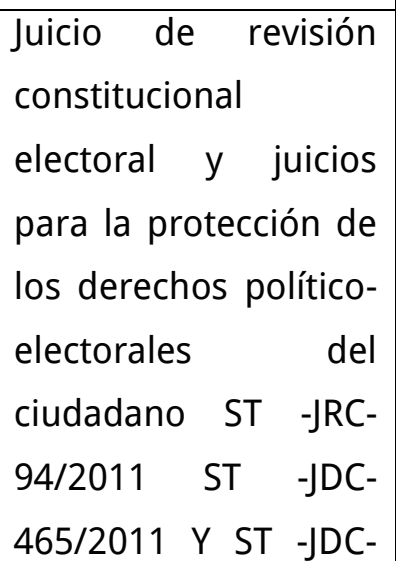 & & $\begin{array}{l}22 \quad \text { de } \\
\text { diciembre } \\
\text { de } 2011\end{array}$ \\
\hline
\end{tabular}


Esta obra forma parte del acervo de la Biblioteca Jurídica Virtual del Instituto de Investigaciones Jurídicas de la UNAM www.juridicas.unam.mx

DOI: http://dx_doï.org/10.22201/ijj.24487910en2015.7.10086

\begin{tabular}{|c|c|c|c|}
\hline & $466 / 2011$ & & \\
\hline 25 & $\begin{array}{lrr}\text { Juicio } & \text { para } & \text { la } \\
\text { protección } & \text { de } & \text { los } \\
\text { derecho } & \text { político- } \\
\text { electorales } & & \text { del } \\
\text { ciudadano } & \text { ST } & \text {-JDC- } \\
488 / 2011 & & \\
\end{array}$ & $\begin{array}{l}\text { Artículo } 197 \text { del Código Electoral del } \\
\text { Estado de Michoacán. }\end{array}$ & $\begin{array}{l}27 \quad \text { de } \\
\text { diciembre } \\
\text { de } 2011\end{array}$ \\
\hline 26 & $\begin{array}{lrr}\text { Juicio } & \text { para } & \text { la } \\
\text { protección } & \text { de } & \text { los } \\
\text { derechos } & \text { político- } \\
\text { electorales } & & \text { del } \\
\text { ciudadano } & \text { SUP-JDC- } \\
14849 / 2011 & \text { y } & \text { SUP- } \\
\text { JDC-25/2012 } & & \end{array}$ & $\begin{array}{l}\text { Último párrafo del artículo } 14 \text { de los } \\
\text { Estatutos Generales del Partido } \\
\text { Acción Nacional, exclusivamente } \\
\text { sobre la suspensión temporal de } \\
\text { derechos partidistas de los } \\
\text { militantes. }\end{array}$ & $\begin{array}{l}19 \text { de enero } \\
\text { de } 2012\end{array}$ \\
\hline 27 & $\begin{array}{lr}\text { Juicio de revisión } \\
\text { constitucional } & \text { SUP- } \\
\text { JRC-10/2012 } & \\
\end{array}$ & $\begin{array}{l}\text { Artículos } 10 \text { y } 47 \text { de la Ley de } \\
\text { Participación Ciudadana del Estado } \\
\text { de Sonora. }\end{array}$ & $\begin{array}{ll}29 & \text { de } \\
\text { febrero } & \text { de } \\
2012 & \end{array}$ \\
\hline 28 & $\begin{array}{lr}\text { Juicios de } & \text { revisión } \\
\text { constitucional } & \text { SUP- } \\
\text { JRC-24/2012 y } & \text { SUP- } \\
\text { JRC-25/2012 } & \end{array}$ & $\begin{array}{l}\text { Fracción I del artículo } 23 \text { de la Ley de } \\
\text { Participación Ciudadana del Estado } \\
\text { de Sonora. }\end{array}$ & $\begin{array}{ll}29 & \text { de } \\
\text { febrero } & \text { de } \\
2012 & \end{array}$ \\
\hline 29 & $\begin{array}{lrr}\text { Juicio } & \text { para } & \text { la } \\
\text { protección } & \text { de } & \text { los } \\
\text { derechos } & \text { político- } \\
\text { electorales } & \text { del } \\
\text { ciudadano } & \text { SDF-JDC- } \\
596 / 2012 & & \end{array}$ & & $\begin{array}{l}4 \text { de junio } \\
\text { de } 2012\end{array}$ \\
\hline 30 & $\begin{array}{lrr}\text { Juicio } & \text { para } & \text { la } \\
\text { protección } & \text { de } & \text { los } \\
\text { derechos } & & \text { político- } \\
\text { electorales } & & \text { del } \\
\text { ciudadano } & \text { SX } & \text {-JDC- }\end{array}$ & $\begin{array}{l}\text { Artículo 68, fracción VI, de la } \\
\text { Constitución Política del Estado de } \\
\text { Chiapas. }\end{array}$ & $\begin{array}{l}27 \text { de junio } \\
\text { de } 2012\end{array}$ \\
\hline
\end{tabular}


Esta obra forma parte del acervo de la Biblioteca Jurídica Virtual del Instituto de Investigaciones Jurídicas de la UNAM www.juridicas.unam.mx tps://biblio.juridicas.unam.mx/bjv

DOI: http://dx_doil.org/10.22201/ijj.24487910en2015.7.10086

\begin{tabular}{|c|c|c|c|}
\hline & $1212 / 2012$ & & \\
\hline 31 & $\begin{array}{l}\text { Juicio de revisión } \\
\text { constitucional SG-JRC- } \\
506 / 2012\end{array}$ & $\begin{array}{l}\text { Artículo 509, párrafo 1, fracción VII y } \\
618, \text { párrafo 1, fracción II, del Código } \\
\text { Electoral y de Participación } \\
\text { Ciudadana del Estado de Jalisco. }\end{array}$ & $\begin{array}{l}14 \text { agosto } \\
\text { de } 2012\end{array}$ \\
\hline 32 & $\begin{array}{l}\text { SUP-REC-202/2012 A } \\
\text { SUP-REC-204/2012 }\end{array}$ & $\begin{array}{l}\text { Artículos 44, fracción VI, de la } \\
\text { Constitución Política del Estado Libre } \\
\text { y Soberano de Guanajuato, y } 282 \text { del } \\
\text { Código de Instituciones y } \\
\text { Procedimientos Electorales de esa } \\
\text { misma entidad. }\end{array}$ & $\begin{array}{l}24 \text { de } \\
\text { septiembre } \\
\text { de } 2012\end{array}$ \\
\hline 33 & $\begin{array}{l}\text { SX -JRC-143/2012, } \\
\text { SX -AG -72/2012 } \\
\text { A SX -AG -74/2012, } \\
\text { SX -JDC-5478/2012 } \\
\text { A SX -JDC-5482/2012, } \\
\text { SX -JDC-5491/2012 } \\
\text { Y SX -JDC-5492/2012, } \\
\text { SX -JDC-5500/2012, } \\
\text { SX -JRC-144/2012 } \\
\text { Y SX -JRC-145/2012 } \\
\text { Y SX -JRC-151/2012 }\end{array}$ & & $\begin{array}{l}26 \text { de } \\
\text { septiembre } \\
\text { de } 2012\end{array}$ \\
\hline 34 & SUP-REC-216/2012 & $\begin{array}{l}\text { El artículo 20, fracción II, de la Ley } \\
\text { Procesal Electoral del Distrito Federal. }\end{array}$ & $\begin{array}{l}30 \text { de } \\
\text { septiembre } \\
\text { de } 2012\end{array}$ \\
\hline 35 & $\begin{array}{lr}\text { Juicio para } & \text { la } \\
\text { protección } & \text { de } \\
\text { derechos } & \text { político- } \\
\text { electorales } & \text { del } \\
\text { ciudadano } & \text { SUP-JDC- }\end{array}$ & $\begin{array}{l}\text { Artículo } 273 \text { del Código Electoral de } \\
\text { Colima. }\end{array}$ & $\begin{array}{l}12 \text { de } \\
\text { diciembre } \\
\text { de } 2012\end{array}$ \\
\hline
\end{tabular}


Esta obra forma parte del acervo de la Biblioteca Jurídica Virtual del Instituto de Investigaciones Jurídicas de la UNAM www.juridicas.unam.mx

DOI: http://dx_doil.org/10.22201/ijj.24487910e_2015.7.10086

\begin{tabular}{|c|c|c|c|}
\hline & $\begin{array}{l}3114 / 2012 \text { Y SUP-JDC- } \\
3115 / 2012, \text { SUP-JDC- } \\
3120 / 2012 \text { Y SUP-JRC- } \\
178 / 2012\end{array}$ & & \\
\hline 36 & 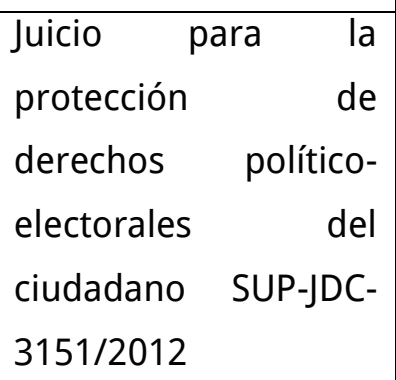 & $\begin{array}{l}\text { Artículo 78, fracción VII; de la Ley } \\
\text { Electoral del Estado de Hidalgo. }\end{array}$ & $\begin{array}{l}9 \text { de enero } \\
\text { de } 2013\end{array}$ \\
\hline 37 & 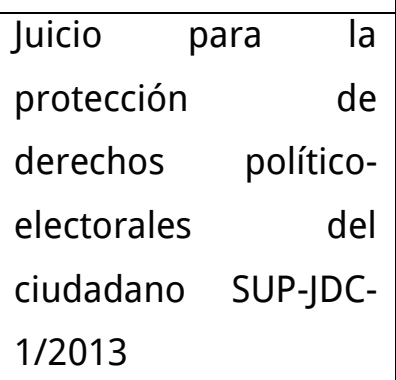 & $\begin{array}{l}\text { Se declara la inaplicación de la } \\
\text { fracción séptima del artículo } 204 \text { de } \\
\text { la Ley Electoral del Estado de Sinaloa. }\end{array}$ & $\begin{array}{l}9 \text { de enero } \\
\text { de } 2013\end{array}$ \\
\hline 38 & 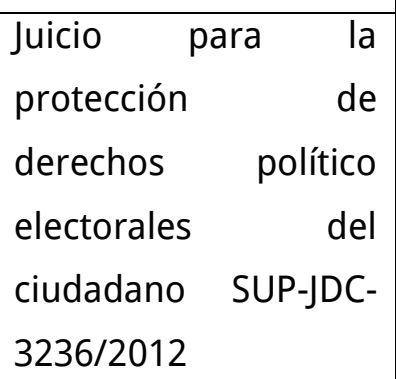 & $\begin{array}{l}\text { Fracción III, inciso c), del artículo } 57 \\
\text { del Código de Instituciones y } \\
\text { Procedimientos Electorales del } \\
\text { Estado de Guanajuato. }\end{array}$ & $\begin{array}{l}23 \text { de enero } \\
\text { de } 2013\end{array}$ \\
\hline 39 & $\begin{array}{lr}\text { Juicio de revisión } \\
\text { constitucional } & \text { SUP- } \\
\text { JRC-195/2012 } & \end{array}$ & $\begin{array}{l}\text { Artículos } 20 \text { de la Constitución } \\
\text { Política del Estado de Tamaulipas y } \\
187 \text { de la Ley Orgánica del Poder } \\
\text { Judicial del referido Estado. }\end{array}$ & $\begin{array}{l}30 \text { de enero } \\
\text { de } 2013\end{array}$ \\
\hline 40 & $\begin{array}{lrr}\text { Juicio } & \text { para } & \text { la } \\
\text { protección } & \text { de } & \text { los } \\
\text { derechos } & \text { político- } \\
\text { electorales } & & \text { del } \\
\text { ciudadano } & \text { SX } & \text {-JDC- } \\
26 / 2013 & & \\
\end{array}$ & & $\begin{array}{ll}13 & \text { de } \\
\text { febrero de } \\
2013\end{array}$ \\
\hline
\end{tabular}


Esta obra forma parte del acervo de la Biblioteca Jurídica Virtual del Instituto de Investigaciones Jurídicas de la UNAM www.juridicas.unam.mx

DOI: http://dx_doi..org/10.22201/iij.24487910e.2015.7.10086

\begin{tabular}{|c|c|c|c|}
\hline 41 & 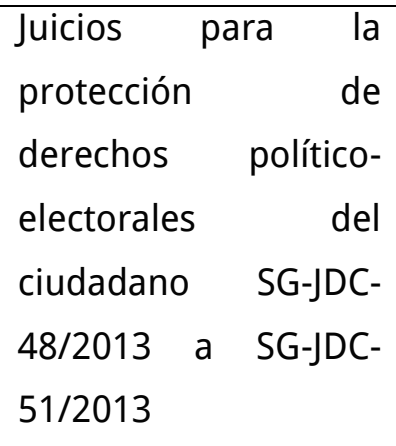 & & $\begin{array}{l}15 \text { de mayo } \\
\text { de } 2013\end{array}$ \\
\hline 42 & $\begin{array}{lrr}\text { Juicio } & \text { para } & \text { la } \\
\text { protección } & \text { de } & \text { los } \\
\text { derechos } & \text { político- } \\
\text { electorales } & & \text { del } \\
\text { ciudadano } & \text { SX } & \text {-JDC- } \\
475 / 2013 & & \\
\end{array}$ & & $\begin{array}{l}20 \text { de junio } \\
\text { de } 2013\end{array}$ \\
\hline 43 & $\begin{array}{lrr}\text { Juicio } & \text { para } & \text { la } \\
\text { protección } & \text { de } & \text { los } \\
\text { derechos } & \text { político- } \\
\text { electorales } & & \text { del } \\
\text { ciudadano } & \text { ST } & \text {-JDC- } \\
91 / 2013 & & \end{array}$ & $\begin{array}{l}\text { Artículo } 288 \text { de los } \\
\text { Partido de la } \\
\text { Democrática. }\end{array}$ & $\begin{array}{l}4 \text { de julio de } \\
2013\end{array}$ \\
\hline 44 & SUP-REC-69/2013 & $\begin{array}{l}\text { Artículo 92, tercer párrafo, de la Ley } \\
\text { de Participación Ciudadana. }\end{array}$ & $\begin{array}{l}18 \text { de julio } \\
\text { de } 2013\end{array}$ \\
\hline 45 & SUP-REC-58/2013 & $\begin{array}{l}\text { Fracción V del artículo } 102 \text { de la Ley } \\
\text { Orgánica de los Municipios de } \\
\text { Tabasco. }\end{array}$ & \begin{tabular}{|ll}
21 & de \\
agosto & de \\
2013 &
\end{tabular} \\
\hline 46 & SUP-REC-87/2013 & $\begin{array}{l}\text { Artículo 56, párrafo 4, de la Ley } \\
\text { Orgánica del Instituto Electoral del } \\
\text { Estado de Zacatecas. }\end{array}$ & $\begin{array}{l}12 \text { de } \\
\text { septiembre } \\
\text { de } 2013\end{array}$ \\
\hline 47 & SUP-REC-138/2013 & $\begin{array}{l}\text { Artículo 123, párrafo cuarto de la Ley } \\
\text { de Participación Ciudadana del } \\
\text { Distrito Federal. }\end{array}$ & $\begin{array}{l}12 \text { de } \\
\text { diciembre } \\
\text { de } 2013\end{array}$ \\
\hline 48 & $\begin{array}{l}\text { Juicios para la } \\
\text { protección de los }\end{array}$ & $\begin{array}{l}\text { Artículos 225, párrafo tercero de la } \\
\text { Ley Orgánica Municipal y } 201 \text { Quater, }\end{array}$ & $\begin{array}{l}11 \text { de abril } \\
\text { de } 2014\end{array}$ \\
\hline
\end{tabular}


Esta obra forma parte del acervo de la Biblioteca Jurídica Virtual del Instituto de Investigaciones Jurídicas de la UNAM www.juridicas.unam.mx

DOI: http://dx_doil.org/10.22201/ijj.24487910en2015.7.10086

\begin{tabular}{|c|c|c|c|}
\hline & 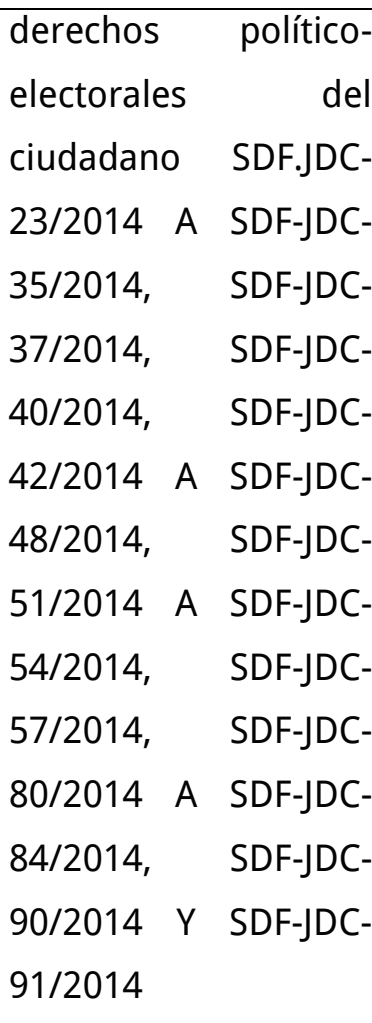 & $\begin{array}{l}\text { fracción I, inciso c) del código local, } \\
\text { cuya reforma fue publicada en el } \\
\text { Periódico Oficial del Estado de Puebla } \\
\text { el } 31 \text { de marzo de } 2014 \text {. }\end{array}$ & \\
\hline 49 & 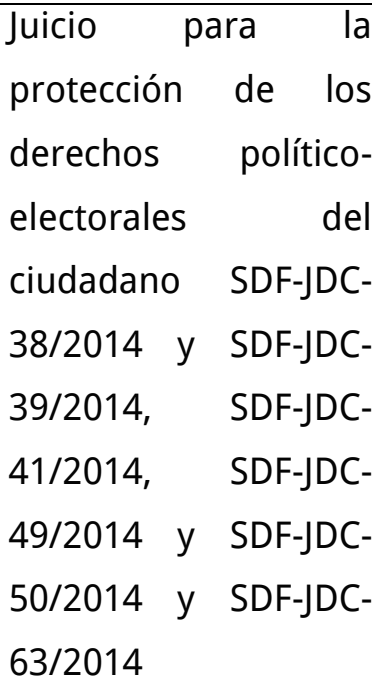 & $\begin{array}{l}\text { Artículos 225, párrafo tercero de la } \\
\text { Ley Orgánica Municipal y } 201 \text { Quater, } \\
\text { fracción I, inciso c) del código local, } \\
\text { cuya reforma fue publicada en el } \\
\text { Periódico Oficial del Estado de Puebla } \\
\text { el } 31 \text { de marzo de } 2014 \text {. }\end{array}$ & $\begin{array}{l}11 \text { de abril } \\
\text { de } 2014\end{array}$ \\
\hline 50 & $\begin{array}{lrr}\text { Juicios } & \text { para } & \text { la } \\
\text { Protección } & \text { de } & \text { los } \\
\text { Derechos } & & \text { Político- } \\
\text { Electorales } & \\
\text { Ciudadano } & \text { SDF-JDC- } \\
58 / 2014 \text { A } & \text { SDF-JDC- } \\
60 / 2014, & & \text { SDF-JDC- }\end{array}$ & $\begin{array}{l}\text { Artículos 225, párrafo tercero de la } \\
\text { Ley Orgánica Municipal y } 201 \text { Quater, } \\
\text { fracción I, inciso c) del Código Local, } \\
\text { cuya reforma fue publicada en el } \\
\text { Periódico Oficial del Estado Puebla el } \\
31 \text { de marzo de } 2014 \text {. }\end{array}$ & $\begin{array}{l}16 \text { de abril } \\
\text { de } 2014\end{array}$ \\
\hline
\end{tabular}


Esta obra forma parte del acervo de la Biblioteca Jurídica Virtual del Instituto de Investigaciones Jurídicas de la UNAM www.juridicas.unam.mx

DOl: http://dx.doi.org/10.22201/ijj.24487910e_2015.7.10086

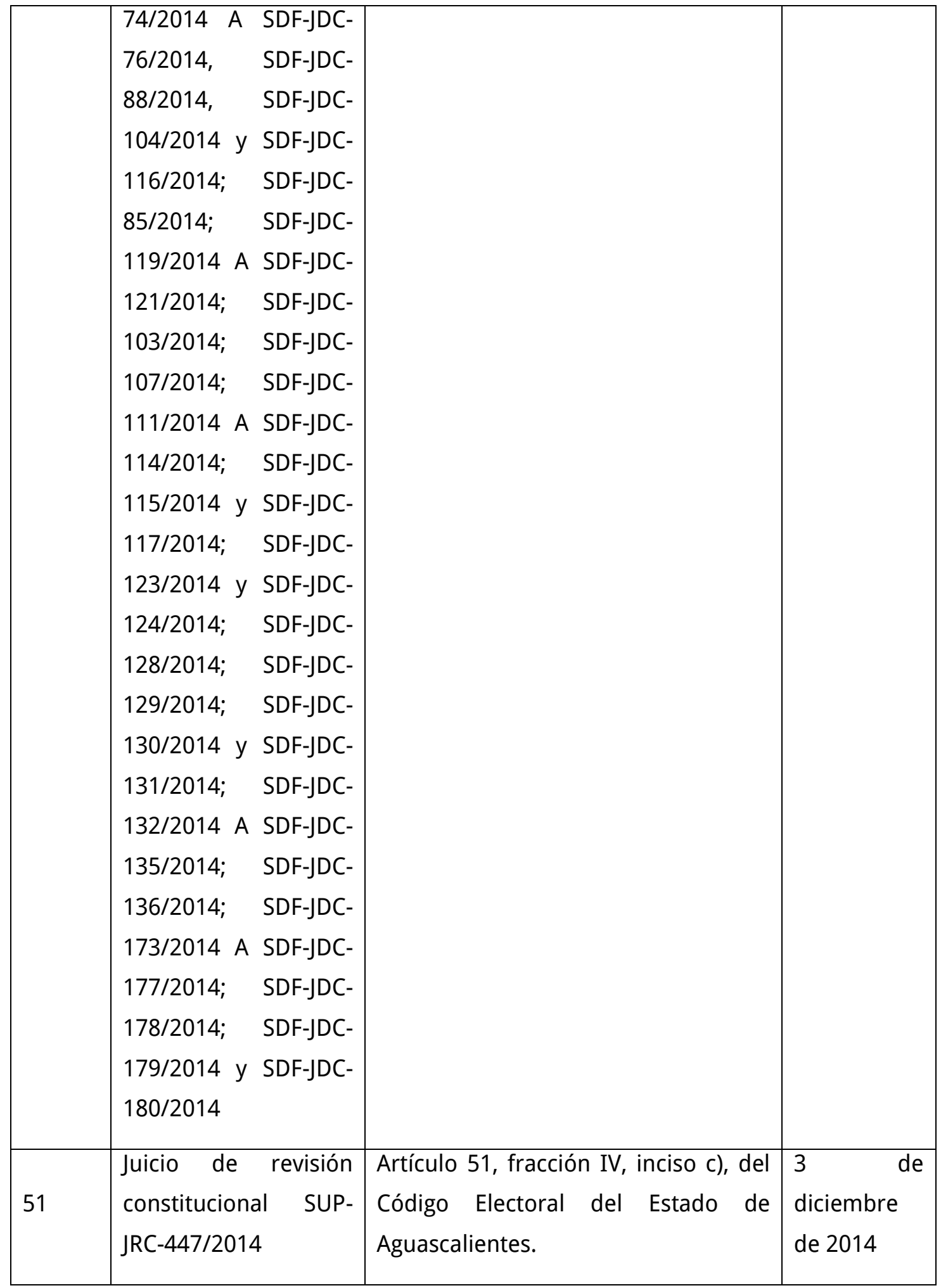

La Sala Superior ha emitido criterios de interpretación y ha dictado jurisprudencia respecto a la competencia reconocida en el párrafo sexto del artículo 99, la cual no es privativa de la Sala Superior, ya que el precepto constitucional se refiere a las "salas" del 
Esta obra forma parte del acervo de la Biblioteca Jurídica Virtual del Instituto de Investigaciones Jurídicas de la UNAM www.juridicas.unam.mx

DOI: http://dx_doil_org/10.22201/iij.24487910e_2015.7.10086

Tribunal (en plural), de modo que las regionales -como se aprecia- están en posibilidad de ejercitar el citado control de constitucionalidad.

En relación con este punto tenemos que las sentencias de las salas regionales en las que se determine la inaplicación de una ley por estimarla contraria a la Constitución, son impugnables ante la propia Sala Superior a través del recurso de reconsideración, ya sea que se trate de una inaplicación implícita o explícita que en su caso realice la Sala Regional (tesis de jurisprudencia 32/2009). ${ }^{37}$

La Sala Superior ha establecido también un criterio relevante relativo a los actos de aplicación, en el que determina que las leyes electorales son susceptibles de control constitucional por las salas del Tribunal Electoral, tantas veces como sean aplicadas, de tal manera que la facultad se puede ejercer con motivo de cualquier acto de aplicación de la norma cuya constitucionalidad se cuestiona, pues no existe disposición que establezca que solamente procederá con motivo del primer acto de aplicación. ${ }^{38}$

\section{ALCANCES Y LÍMITES DEL CONTROL}

Como ya hemos visto, el tipo de control que realiza el TEPJF es de carácter concreto, de manera que el alcance del mismo se limita en sus efectos a las partes que contiendan en un juicio específico. Como es obvio, no será posible que el Tribunal declare inválida o nula la disposición que se juzgue inconstitucional (control abstracto, que es exclusivo de la SCJN) sino que su competencia se constriñe a la inaplicación de la disposición en el caso específico.

Debe hacerse notar, como lo señala David Cienfuegos, que al fungir como salas de jurisdicción constitucional, los criterios que emita el TEPJF serán invocados por los justiciables ante los tribunales o salas electorales locales, con mayor o menor fuerza. ${ }^{39}$ Creemos, no obstante, que si bien es cierto que lo anterior puede subsanar en alguna

${ }^{37}$ El rubro de la tesis de jurisprudencia 32/2009 es: RECURSO DE RECONSIDERACIÓN. PROCEDE SI EN LA SENTENCIA LA SALA REGIONAL INAPLICA, EXPRESA O IMPLÍCITAMENTE, UNA LEY ELECTORAL POR CONSIDERARLA INCONSTITUCIONAL.

${ }^{38}$ Tesis XXXIII/2009 de la Sala Superior, cuyo rubro señala: InCONSTITUCIONALIDAD DE LEYES ELECTORALES. Se PUEDE PLANTEAR POR CADA ACTO DE APLICACIÓN.

${ }^{39}$ Cienfuegos Salgado, David, "Acerca de las nuevas atribuciones de las salas regionales del Tribunal Electoral del Poder Judicial de la Federación", Revista Lex, México, Tercera Época, año XII, núm. 158, agosto de 2008, p. 79. 
Esta obra forma parte del acervo de la Biblioteca Jurídica Virtual del Instituto de Investigaciones Jurídicas de la UNAM

medida las restricciones que emanan del control concreto (ya que los precedentes "generalizarían" en alguna medida las resoluciones del Tribunal), el conflicto está lejos de solucionarse, pues ello sólo podría ser beneficioso para quien esté en condiciones de promover un juicio.

Por ejemplo, una autoridad podría seguir fundando sus actos en leyes inconstitucionales (incluso las que ya hayan sido estimadas como tales por el TEPJF en el pasado) y si éstos no se impugnan, subsistirán sus efectos. Es de reiterar que el control concreto genera - para todo efecto práctico - que la misma ley sea "inconstitucional" para unos y "constitucional" para otros.

De hecho, se ha dado el caso que el Tribunal inaplique más de una vez la misma norma. Esto ocurrió cuando la Sala Regional de Guadalajara determinó la no aplicación de una disposición de la Constitución Política del Estado Libre y Soberano de Chihuahua, por contravenir lo dispuesto en el artículo 115 de la Constitución federal, el cual prohíbe que los ciudadanos sean elegibles en el periodo siguiente como miembros del órgano político municipal. ${ }^{40}$ Con ello, se declaró la inelegibilidad de dos candidatos que habían sido registrados con base en la disposición local antes referida.

Desde nuestra óptica, el control concreto acarrea un problema que se relaciona con la garantía de acceso a la justicia, en especial cuando se trata de ciudadanos comunes que acuden al TEPJF a promover un juicio para la protección de sus derechos políticoelectorales y que no en todos los casos tienen las posibilidades de instaurar un juicio tan fácilmente. Este problema se agudiza por la brevedad de los plazos que se exigen en la materia electoral por su naturaleza. El ciudadano tiene un plazo para presentar su demanda de apenas cuatro días. ${ }^{41}$ Como en el caso del amparo contra leyes, en el que se ha suprimido el principio de relatividad en las sentencias, en la materia electoral no tendría por qué hacerse una excepción, de modo que es imperioso reconocer la posibilidad de que las salas del TEPJF ejerzan un control abstracto de constitucionalidad.

\footnotetext{
${ }^{40}$ Expedientes: SG-JDC-29/2010 y SG-JRC-38/2010.

${ }^{41}$ El artículo 80., párrafo 1, de la Ley General del Sistema de Medios de Impugnación en Materia Electoral señala: 1. Los medios de impugnación previstos en esta ley deberán presentarse dentro de los cuatro días contados a partir del día siguiente a aquél en que se tenga conocimiento del acto o resolución impugnado, o se hubiese notificado de conformidad con la ley aplicable, salvo las excepciones previstas expresamente en el presente ordenamiento.
} 
Esta obra forma parte del acervo de la Biblioteca Jurídica Virtual del Instituto de Investigaciones Jurídicas de la UNAM

\section{CONCLUSIONES}

Los medios de impugnación electorales de los que conoce el TEPJF son la única vía que tiene un ciudadano común para inconformarse por una ley presumiblemente inconstitucional que afecta sus derechos políticos, ya que los otros dos posibles medios de control le están negados en el derecho mexicano: a) el juicio de amparo contra leyes es improcedente en materia electoral, y b) la acción de inconstitucionalidad sólo reconoce legitimación a ciertos sujetos entre los que no se encuentran los ciudadanos como tales.

La reforma electoral (2007-2008) constituyó un salto muy grande respecto al estado de cosas anterior, ya que desde mayo de 2002 el TEPJF se encontraba impedido por la SCJN para verificar la constitucionalidad de una ley electoral. Ello a causa de un criterio que canceló al ciudadano aquella única vía con la que contaba para acceder a la justicia constitucional en la materia. Con la reforma se devolvió al órgano jurisdiccional electoral la posibilidad de realizar un control difuso como el que ejerció antes de 2002, a través del cual inaplique una ley electoral contraria a la Constitución.

Esto quiere decir que con sus sentencias el TEPJF realiza un control concreto de constitucionalidad, pero encontramos un problema. Si consideramos que existen dos tipos de leyes, las constitucionales y las inconstitucionales, puede decirse que en el sistema de control concreto, una ley puede ser ambas a la vez. Será inconstitucional para quien haya comparecido a juicio y obtenga una sentencia favorable, mientras que será constitucional para el resto de los mortales. El problema no sólo es de lógica sino de seguridad jurídica.

En el derecho anglosajón (de donde no es casual que provenga ese tipo de control) tienen un antídoto para ello, pues rige el principio stare decisis (vinculación del precedente). Con ello, las sentencias previas van obligando a los jueces a resolver en una misma línea, de manera que los efectos particulares tienden a generalizarse. No ocurre lo mismo - cuando menos no al mismo grado- en los sistemas de derecho continental o romano-civilistas, como es el caso de México; por lo tanto, es en éstos donde el control concreto (con efectos inter partes) es especialmente pernicioso.

En el otro extremo, el control abstracto tiene la ventaja de brindar mayor seguridad jurídica (si una ley se declara inconstitucional, tendrá ese carácter para todas las personas porque se extingue su vigencia). Pero no todo es miel sobre hojuelas: este 
Esta obra forma parte del acervo de la Biblioteca Jurídica Virtual del Instituto de Investigaciones Jurídicas de la UNAM

sistema exige una mayor responsabilidad de los tribunales y jueces; si un juez se equivoca, su pifia también tiene efectos generales; si hace un uso abusivo de su función, puede haber consecuencias funestas en el equilibrio de poderes. Para reducir estos riesgos, estimamos adecuado exigir una mayoría calificada de votos para que la sentencia pueda invalidar leyes por inconstitucionalidad.

México, en este sentido, tiene un sistema mixto. Actualmente el control constitucional electoral se integra con la acción de inconstitucionalidad a cargo de la SCJN y con los medios de impugnación electorales que conoce el TEPJF. Sin embargo, llama la atención que sólo las sentencias de la SCJN pueden tener efectos generales cuando debieran ser ambos órganos, máxime que el Tribunal Electoral es competente para conocer del juicio para la protección de los derechos político-electorales del ciudadano.

Debe tenerse presente que, ante una norma contraria a la Constitución, sólo los individuos que dispongan de la información y de los recursos necesarios (la posibilidad económica de contratar un abogado, por ejemplo), podrán recibir la protección de la justicia federal ante una ley inconstitucional que les afecte. Los actores legitimados para acudir a la SCJN a promover una controversia constitucional (grupos de legisladores, partidos y determinadas instituciones públicas), no parecen tener problema. Pero sí los ciudadanos "de a pie" que acuden al TEPJF en busca de justicia, lo mismo que - fuera de la materia electoral-sucedió por mucho tiempo con el amparo contra leyes.

Este problema se ve agravado por la naturaleza propia de la materia electoral en la que los plazos son muy breves. El ciudadano queda en una condición precaria ya que para presentar su demanda cuenta con apenas cuatro días, plazo bastante menor que el previsto para que se promueva una acción de inconstitucionalidad ante la SCJN (30 días).

Por estas razones concluimos que, si bien la reforma constitucional de 2007 constituyó un avance significativo en la materia, hace falta otro paso: que se reconozca en el artículo 99 constitucional la posibilidad de que el TEPJF efectúe un control abstracto de constitucionalidad de leyes electorales de modo que sus sentencias lleguen a producir efectos erga omnes. En congruencia con lo que sucede en las acciones de inconstitucionalidad, la propuesta concreta es que se exija una mayoría calificada que sea superior a las dos terceras partes: cinco magistrados de la Sala Superior (71.4\%) y tres magistrados para el caso de las Salas Regionales (100\%).

Tengo la convicción de que una reforma que contemple la declaratoria general de 
Esta obra forma parte del acervo de la Biblioteca Jurídica Virtual del Instituto de Investigaciones Jurídicas de la UNAM www.juridicas.unam.mx

DOI: http://dx_doi.org/10.22201/iij_24487910e_2015.7.10086

inconstitucionalidad en toda la jurisdicción constitucional electoral, significaría un plus en seguridad jurídica para los ciudadanos, y una forma más acabada de acceso a la justicia en esta materia.

DR (C) 2018. Instituto de Investigaciones Jurídicas, UNAM, https://revistas.juridicas.unam.mx/index.php/derecho-electoral/issue/archive 